\title{
Temperature-dependent changes in the host-seeking behaviors of parasitic nematodes
}

\author{
Joon Ha Lee ${ }^{1}$, Adler R. Dillman² and Elissa A. Hallem ${ }^{\text {* }}$
}

\begin{abstract}
Background: Entomopathogenic nematodes (EPNs) are lethal parasites of insects that are of interest as biocontrol agents for insect pests and disease vectors. Although EPNs have been successfully commercialized for pest control, their efficacy in the field is often inconsistent for reasons that remain elusive. EPN infective juveniles (IJs) actively search for hosts to infect using a diverse array of host-emitted odorants. Here we investigate whether their host-seeking behavior is subject to context-dependent modulation.

Results: We find that EPN IJs exhibit extreme plasticity of olfactory behavior as a function of cultivation temperature. Many odorants that are attractive for IJs grown at lower temperatures are repulsive for IJs grown at higher temperatures and vice versa. Temperature-induced changes in olfactory preferences occur gradually over the course of days to weeks and are reversible. Similar changes in olfactory behavior occur in some EPNs as a function of IJ age. EPNs also show temperature-dependent changes in their host-seeking strategy: IJs cultured at lower temperatures appear to more actively cruise for hosts than IJs cultured at higher temperatures. Furthermore, we find that the skin-penetrating rat parasite Strongyloides ratti also shows temperature-dependent changes in olfactory behavior, demonstrating that such changes occur in mammalian-parasitic nematodes.

Conclusions: IJs are developmentally arrested and long-lived, often surviving in the environment through multiple seasonal temperature changes. Temperature-dependent modulation of behavior may enable IJs to optimize host seeking in response to changing environmental conditions, and may play a previously unrecognized role in shaping the interactions of both beneficial and harmful parasitic nematodes with their hosts.
\end{abstract}

Keywords: Parasitic nematodes, Entomopathogenic nematodes, Host-seeking behavior, Olfaction, Olfactory plasticity

\section{Background}

The widespread use of chemical insecticides in agriculture is a growing health and ecological concern, with an increasing number of studies revealing detrimental effects on organisms such as non-pest insects, aquatic animals, and humans [1-4]. Commonly explored alternatives to synthetic chemical pesticides include natural pesticides and transgenic plants expressing insecticidal protectants $[5,6]$. However, natural pesticides often present a toxicity concern and genetically modified organisms remain a topic of public debate and controversy $[4-8]$.

\footnotetext{
* Correspondence: ehallem@microbio.ucla.edu

'Department of Microbiology, Immunology, and Molecular Genetics,

University of California, Los Angeles, California 90095, USA

Full list of author information is available at the end of the article
}

Entomopathogenic nematodes (EPNs) of the genera Steinernema and Heterorhabditis are lethal parasites of insects that are used throughout the world as biocontrol agents for insect pests [9]. EPNs offer a number of advantages as biocontrol agents - they are found on all continents except Antarctica and are therefore considered non-invasive [10], kill a wide variety of insect agricultural pests [11], are amenable to low-cost mass production [12], and are considered safe to humans and the environment [13]. However, while EPNs are used successfully against some insect pests [14], their efficacy in the field is often inconsistent, precluding their widespread use [14-16]. A number of variables have been found to influence their effectiveness, including temperature, humidity, soil type, and timing of 
application [16]. Nevertheless, reliable predictors of field efficacy remain lacking.

Host-seeking behavior is a critical aspect of EPN biology that is poorly understood in relation to biocontrol. Like many parasitic nematodes, EPNs infect insects as infective juveniles (IJs), which are developmentally arrested third-stage larvae analogous to the dauer larvae of free-living nematodes [17] (Fig. 1a). IJs are longlived, non-feeding, and stress-resistant [17-19], and seek out hosts using chemosensory cues [20, 21]. They are attracted to the respiratory byproduct carbon dioxide $\left(\mathrm{CO}_{2}\right)$ as well as a diverse array of host-specific odorants, with different species showing different odor response profiles [22-24]. IJs are also attracted to plant odorants, including some that are emitted in response to insect predation [25-29]. A comparison of olfactory behavior in EPNs and other parasitic nematodes revealed that olfactory preferences reflect host specificity rather than phylogeny $[22,30]$, suggesting that olfaction plays an important role in host selection for these parasites.

EPNs vary not only in their olfactory preferences, but also in their host-seeking strategies. Some are cruisers that actively search for hosts, some are ambushers that attack passing hosts, and some use an intermediate strategy (Fig. 1b) [31, 32]. Despite differences in host-seeking strategy, all EPNs show robust chemotaxis to live hosts and host-derived odorants [22-24, 30, 33-35]. Thus, although ambushers and cruisers show different behaviors in the absence of host stimuli, both are capable of migrating toward hosts in response to host-emitted sensory cues.

During the course of previous experiments examining the responses of EPNs to host-emitted odorants, we were surprised to discover that olfactory behavior appeared to vary depending on IJ cultivation temperature and age. Temperature and age are known to modulate feeding, mating, learning and memory, and other biological processes in many different animals [36-44]. However, little is known about whether they alter olfactory sensory valence - i.e., whether an odorant is attractive or repulsive - or foraging strategy. To investigate this further, we conducted an in-depth analysis of the effects of cultivation temperature and IJ age on the host-seeking behaviors of six EPN species.

We found that EPNs showed dramatic changes in olfactory behavior and host-seeking strategy as a function of cultivation temperature and age. Temperatureinduced changes were reversible over the course of days to weeks. We also found that one of the EPNs tested, the cricket specialist Steinernema scapterisci, showed age-dependent changes in $\mathrm{CO}_{2}$ response that correlated with changes in the response to insect hosts. Thus, both generalist and specialist EPNs exhibit extreme olfactory plasticity as a function of temperature and/or age. To test whether olfactory plasticity occurs in other types of parasitic nematodes, we examined the skin-penetrating rat parasite Strongyloides ratti, a close relative of the human threadworm Strongyloides stercoralis. We found that Str. ratti also exhibits temperature-dependent olfactory plasticity, suggesting that olfactory plasticity may be widespread among parasitic nematodes.

Taken together, our results demonstrate that host seeking is context-dependent and describe a novel behavioral plasticity with broad implications for the interactions of both beneficial and harmful parasitic nematodes with their hosts. Temperature and age often vary during commercial application of EPNs, and our results suggest that this variability will cause changes in host-seeking behavior that may alter the efficacy of EPNs as biocontrol agents. In addition, parasitic nematodes of humans, livestock, and plants cause extensive disease and economic loss worldwide [45-47]. Our results raise the possibility that a better understanding of their olfactory plasticity could enable the development of targeted odor-based traps or repellents for preventing harmful infections.

\section{Results}

Steinernema carpocapsae olfactory responses are modulated by temperature

We first examined the olfactory behavior of Steinernema carpocapsae, an EPN with a broad geographical distribution

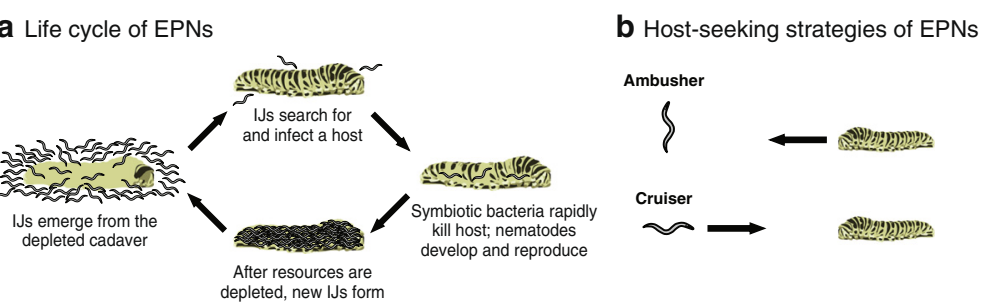

Fig. 1 Life cycle and host-seeking strategies of entomopathogenic nematodes (EPNs). a The EPN life cycle. Infective juveniles (IJs) search for hosts in the environment. Once a host is identified, IJs infect the host and release endosymbiotic bacteria harbored in their gut, which rapidly kill the host [48]. IJs then resume development and reproduce until resources are depleted, at which point new IJs form and emerge from the host cadaver to search for new hosts. Adapted from Hallem et al. [22]. b Host-seeking strategies of EPNs. Ambushers wait for hosts to approach; cruisers migrate through their environment in search of hosts [21] 
that is widely used for insect control [14]. To test whether cultivation temperature affects the olfactory behavior of Ste. carpocapsae IJs, we cultured nematodes at either $15{ }^{\circ} \mathrm{C}$, $20{ }^{\circ} \mathrm{C}$, or $25^{\circ} \mathrm{C}$ and examined the olfactory responses of IJs 4 weeks after emergence from the insect host. Responses were tested in a chemotaxis assay, in which IJs were allowed to migrate toward or away from an odorant source (Additional file 1: Figure S1). We examined the responses of IJs to a chemically diverse panel of odorants that included known EPN attractants and repellents as well as odorants previously found to be emitted by potential insect hosts $[22,23]$.

We found that IJs showed dramatic differences in their olfactory preferences depending on their cultivation temperature. The responses to $80 \%$ of the tested odorants changed depending on the cultivation temperature of the IJs, and nearly half of these changes resulted in responses of opposite valence (Fig. 2). For example, methyl acetate and 2-propanone elicited attractive responses from $15{ }^{\circ} \mathrm{C}$ IJs, repulsive responses from $25{ }^{\circ} \mathrm{C}$ IJs, and intermediate responses from $20{ }^{\circ} \mathrm{C}$ IJs. The reverse was true for long-chain alcohols such as 1-hexanol and 1heptanol, which were repulsive for $15{ }^{\circ} \mathrm{C}$ IJs but attractive for $20{ }^{\circ} \mathrm{C}$ and $25^{\circ} \mathrm{C}$ IJs. Changes in olfactory behavior occurred gradually across temperature ranges, such that IJs exhibited intermediate responses for intermediate temperature points (Additional file 2: Figure S2A). Furthermore, these changes in response valence with IJ cultivation temperature were seen regardless of the assay temperature; for example, IJs cultivated at $15{ }^{\circ} \mathrm{C}$ showed similar olfactory preferences when assayed at both $15{ }^{\circ} \mathrm{C}$ and room temperature (Additional file 2: Figure S2B). Thus, the observed differences in response valence among cultivation conditions were not due to acute acclimation to the assay temperature.

\section{Ste. carpocapsae exhibits temperature-induced olfactory plasticity}

We next tested whether temperature changes can alter olfactory behavior. For this experiment, nematodes were cultured at $25{ }^{\circ} \mathrm{C}$ and day 0 IJs were tested for their responses to 2-propanone and 1-hexanol, two odorants that showed dramatic temperature-dependent valence changes in opposite directions. As expected, 2propanone was strongly repulsive and 1-hexanol was strongly attractive (Fig. 3a). IJs were then temperatureswapped to $15{ }^{\circ} \mathrm{C}$, maintained at $15{ }^{\circ} \mathrm{C}$ for 2 weeks, and tested on day 14 . After 2 weeks at $15{ }^{\circ} \mathrm{C}$, IJs showed dramatically different olfactory responses: 2-propanone was strongly attractive and 1-hexanol was neutral. Day 14 IJs were then temperature-swapped back to $25{ }^{\circ} \mathrm{C}$ and tested at 4 weeks, at which point olfactory responses had shifted back: 2-propanone was again strongly repulsive and 1-hexanol was strongly attractive

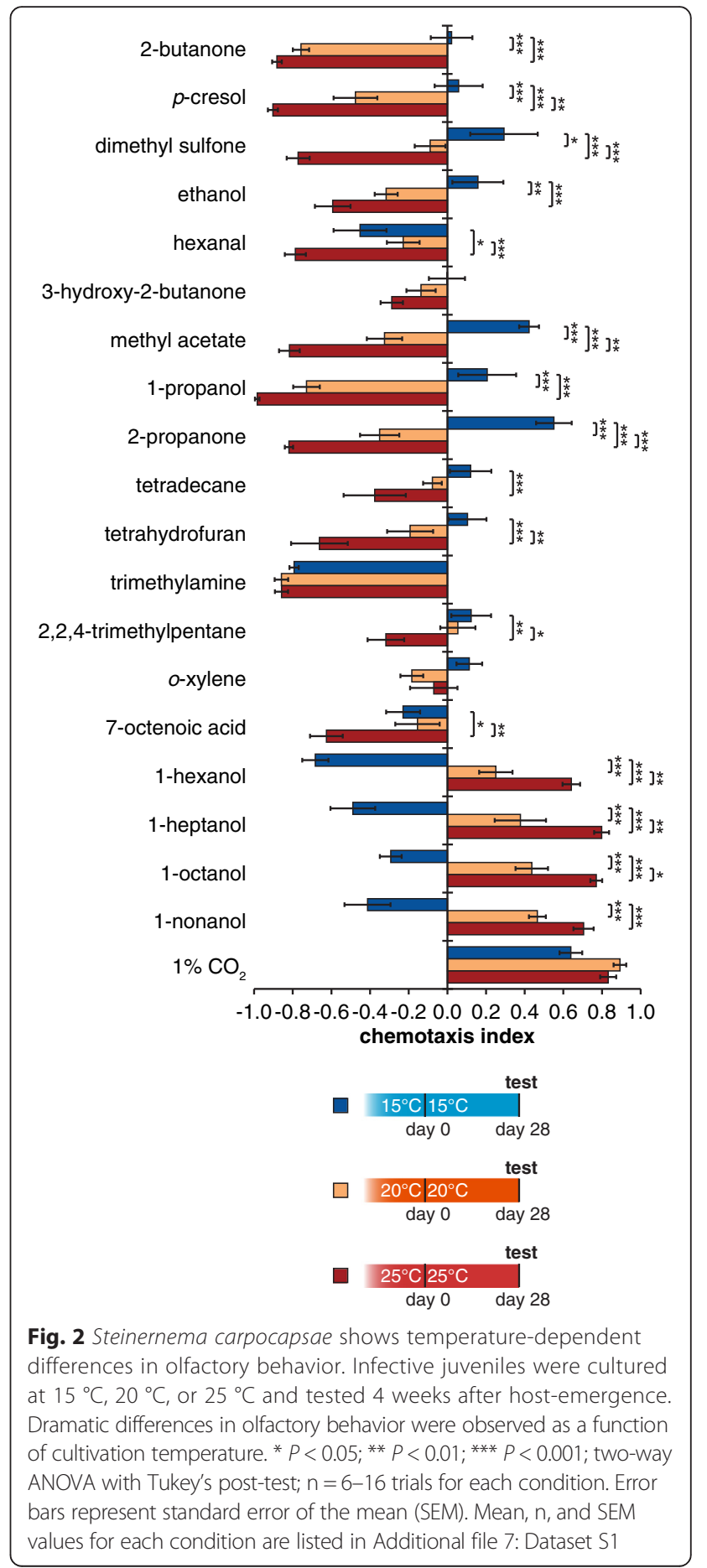

(Fig. 3a). Thus, temperature changes induce reversible changes in olfactory behavior. Similar plasticity was observed with older IJs, although olfactory responses changed more slowly in older IJs than younger IJs (Fig. 3b, c). By contrast, 2-propanone remained repulsive and 1-hexanol remained attractive for IJs maintained at $25{ }^{\circ} \mathrm{C}$ (Fig. 3d). 


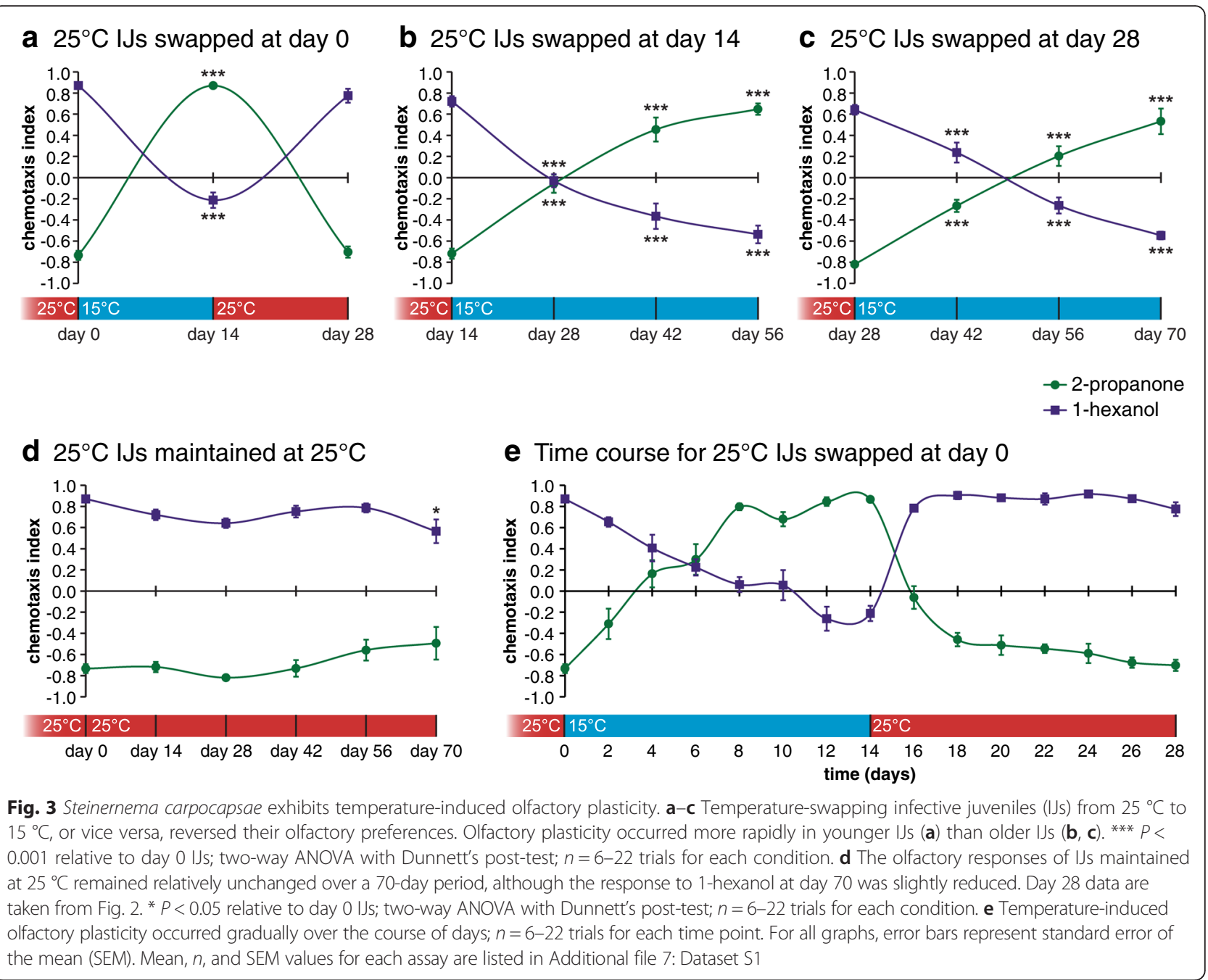

The robust differences in response valence between IJs maintained at $25{ }^{\circ} \mathrm{C}$ and IJs temperature-swapped from $25{ }^{\circ} \mathrm{C}$ to $15{ }^{\circ} \mathrm{C}$ were observed regardless of the assay temperature (Additional file 2: Figure S2C). Dose-response analysis for the different IJ populations revealed that olfactory preferences were consistent across $\mathrm{CO}_{2}$ and odorant concentrations (Additional file 3: Figure S3A, B), indicating that temperature changes primarily alter valence. IJs exhibited olfactory plasticity in response to blends of odorants at lower concentrations (Additional file 3: Figure S3C), suggesting the results for individual odorants can be generalized to odorant mixtures. In addition to affecting response valence, temperature and age may also affect response sensitivity, as $25{ }^{\circ} \mathrm{C}$ IJs aged for 14 days showed increased attraction to $0.5 \% \mathrm{CO}_{2}$ and increased repulsion to low concentrations of 2-propanone (Additional file 3: Figure S3A, B). To investigate effects on sensory valence rather than sensitivity, we chose to focus on $1 \% \mathrm{CO}_{2}$ and undiluted odorants for all further experiments. Changes in olfactory preferences occurred in individual IJs and in multiple strains of Ste carpocapsae, and were not affected by IJ cultivation density (Additional file 4: Figure S4). Taken together, these results demonstrate that individual IJs exhibit olfactory plasticity in response to temperature changes.

We then examined the rate at which olfactory responses change in temperature-swapped IJs by testing responses to 2-propanone and 1-hexanol every 2 days following the temperature swap. We found that temperature-induced changes in olfactory preferences occurred gradually over the course of days to weeks (Fig. 3e). These results are consistent with olfactory plasticity being a response to seasonal, but not diurnal, temperature variation.

\section{Olfactory responses are stable in the absence of a temperature change}

To examine the stability of IJ olfactory responses in the absence of a temperature change, we examined the behavior of IJs that were cultured at room temperature, 
temperature-swapped to $15{ }^{\circ} \mathrm{C}$ on day 0 , and maintained at $15{ }^{\circ} \mathrm{C}$ for up to 4 months. We found that, after the initial change in olfactory behavior induced by the temperature swap, olfactory preferences remained unchanged for up to 4 months (Additional file 5: Figure S5). Thus, olfactory preferences exhibit long-term stability under constant temperature conditions.

\section{Temperature- and age-dependent changes in olfactory behavior occur broadly across EPN species}

EPNs of the genera Steinernema and Heterorhabditis are distantly related but have similar lifestyles as a result of convergent evolution [48, 49]. Despite their similar lifestyles, different EPNs show different odor response profiles, which are thought to reflect their host specificities [22, 23]. To test whether olfactory plasticity occurs in EPNs other than Ste. carpocapsae, we examined the responses of five additional species Steinernema riobrave, Steinernema feltiae, Steinernema scapterisci, Heterorhabditis bacteriophora, and Heterorhabditis indica - under the same cultivation conditions to an 8-odorant panel comprised of odorants that were previously shown to elicit robust responses from different EPNs [22, 30]. Ste. feltiae, H. bacteriophora, and $H$. indica have broad geographical distributions and are used to control a wide variety of insect pests [50], while Ste. riobrave is a warm-adapted strain with a narrower geographical distribution and host range [50]. Ste. scapterisci is a specialist known to preferentially infect crickets and has been shown to be effective in lowering populations of Scapteriscus spp. mole crickets in Florida [51, 52]. For these experiments, nematodes were cultured at $25{ }^{\circ} \mathrm{C}$ and IJs were either maintained at $25{ }^{\circ} \mathrm{C}$ or temperature-swapped to $15{ }^{\circ} \mathrm{C}$ after emergence from the host. For comparison, we examined the responses of Ste. carpocapsae to the same eight-odorant panel under these conditions.

Similar to what we observed with our larger odorant panel, we found that the olfactory responses of Ste. carpocapsae IJs cultured at $25{ }^{\circ} \mathrm{C}$ and then temperatureswapped to $15{ }^{\circ} \mathrm{C}$ changed dramatically, while the olfactory responses of IJs maintained at $25{ }^{\circ} \mathrm{C}$ remained relatively unchanged. Half of the tested odorants were attractive to $25{ }^{\circ} \mathrm{C}$ IJs regardless of age, but repulsive or neutral to IJs temperature-swapped from $25{ }^{\circ} \mathrm{C}$ to $15{ }^{\circ} \mathrm{C}$ (Additional file 6: Figure S6A). By contrast, $H$. bacteriophora olfactory responses changed primarily as a function of age rather than temperature - responses were not significantly different following the temperature change but were significantly different in older IJs regardless of the cultivation temperature (Additional file 6: Figure S6B and Fig. 4a, b). For example, all of the tested odorants except $\mathrm{CO}_{2}$ elicited significantly different responses from $25{ }^{\circ} \mathrm{C}$ IJs at day
0 versus day 28, and three of the eight odorants elicited responses of opposite valence (Fig. 4b). Agedependent changes were less extreme at $15^{\circ} \mathrm{C}$ within the time frame examined (Fig. 4a), most likely because agerelated changes occur more slowly at $15{ }^{\circ} \mathrm{C}$ than $25{ }^{\circ} \mathrm{C}$. Temperature-swap experiments with $25^{\circ} \mathrm{C}$ IJs swapped to $15{ }^{\circ} \mathrm{C}$ and back to $25^{\circ} \mathrm{C}$ showed a switch in valence over time (Fig. 4c). This change in olfactory behavior was also observed with IJs maintained at $25^{\circ} \mathrm{C}$ (Fig. $4 \mathrm{~d}$ ). These results are consistent with $H$. bacteriophora showing agedependent changes in olfactory preferences.

The four other EPNs tested - Ste. scapterisci, Ste. riobrave, $H$. indica, and Ste. feltiae - exhibited both age- and temperature-dependent changes in olfactory behavior, although to varying extents (Additional file 6: Figure S6C-F). For example, temperature effects were seen with the response of Ste. scapterisci to 1-heptanol, Ste. riobrave to methyl salicylate, $H$. indica to 1-hexanol, and Ste. feltiae to $\mathrm{CO}_{2}$, where IJs temperature-swapped to $15{ }^{\circ} \mathrm{C}$ showed significant differences from $25{ }^{\circ} \mathrm{C}$ IJs. On the other hand, age effects were seen with the response of Ste. scapterisci to methyl salicylate, Ste. riobrave to benzaldehyde, H. indica to 6-methyl-5-hepten-2-one, and Ste. feltiae to 2-methyl-1-butanol, where day 0 and 14 IJs showed significant differences regardless of temperature treatment. Taken together, these data suggest that temperature- and age-dependent effects in olfactory behavior are broadly conserved across EPN species, though the extent of these changes varies across different species and different odorants. Moreover, these results demonstrate that IJs show age-dependent changes in sensory behavior even though they are developmentally arrested.

\section{Ste. scapterisci shows an age-dependent change in its response to $\mathrm{CO}_{2}$ and insect hosts}

$\mathrm{CO}_{2}$ is emitted by all aerobic organisms, including insects, and is strongly attractive for EPNs as well as many other parasitic animals [21-23]. Moreover, $\mathrm{CO}_{2}$ is an essential host cue for EPNs; in the absence of $\mathrm{CO}_{2}$, attraction to host odor blends is greatly reduced or eliminated $[22-24,53]$. Most of the species tested were robustly attracted to $\mathrm{CO}_{2}$ regardless of temperature or age, consistent with $\mathrm{CO}_{2}$ being an essential host cue (Figs. 2, 4, Additional file 3: Figure S3A and Additional file 6: Figure S6). Because it is so ubiquitous in nature, it is thought of as a general host cue. Thus, the stable attraction to $\mathrm{CO}_{2}$ may direct parasitic worms to live animals, whereas olfactory plasticity may allow for context-dependent modulation of host discrimination. However, we were surprised to find that the cricket specialist Ste. scapterisci was repelled by $\mathrm{CO}_{2}$ under the conditions tested (Additional file 6: Figure $\mathrm{S6C}$ ), which was in contrast to our previous finding that Ste. scapterisci is attracted to $\mathrm{CO}_{2}$ [23]. We 


\section{a $H$. bacteriophora, maintained at $15^{\circ} \mathrm{C}$}

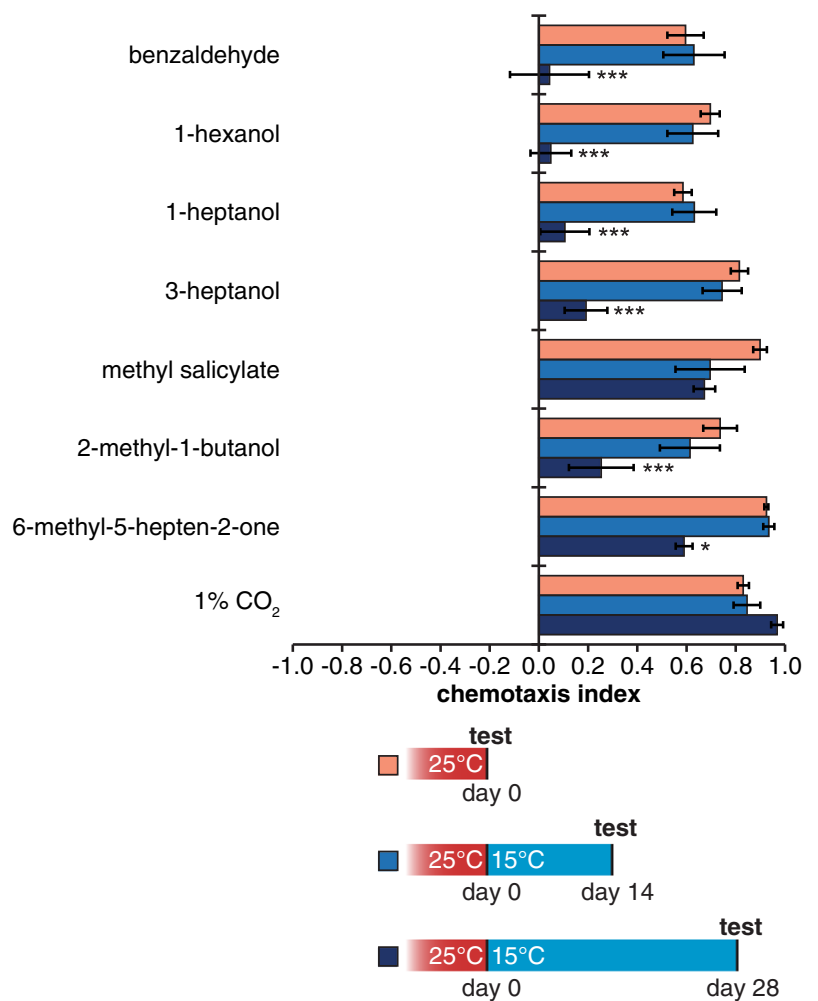

b $H$. bacteriophora, maintained at $25^{\circ} \mathrm{C}$

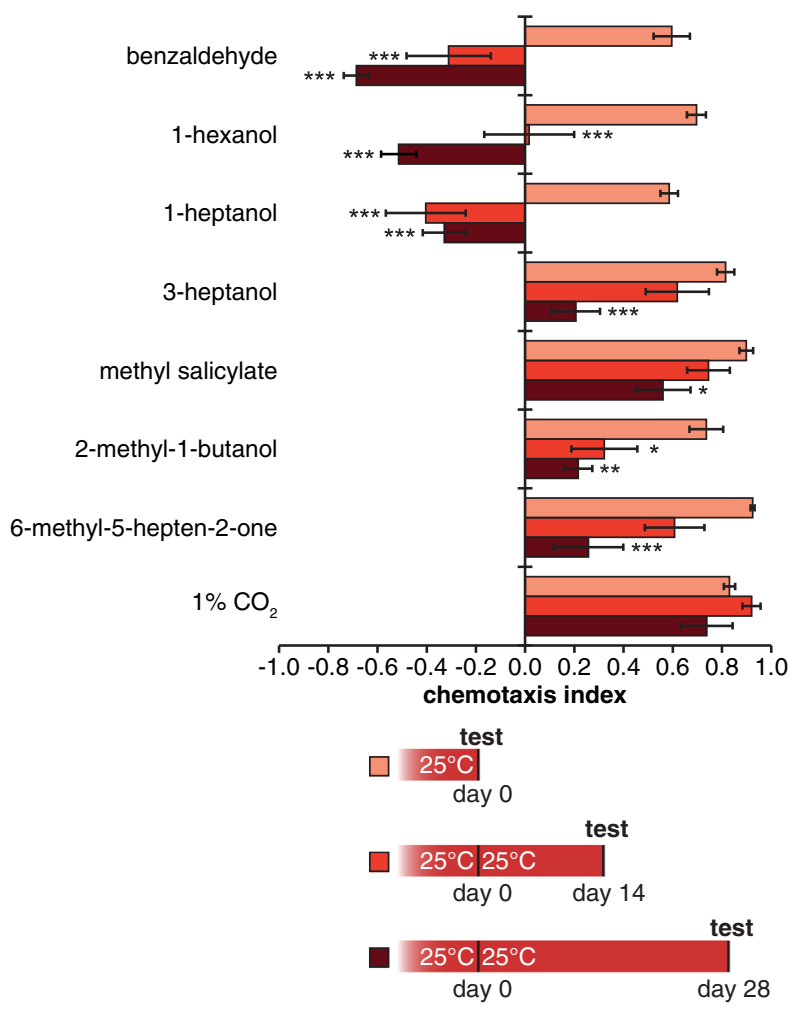

\section{c $25^{\circ} \mathrm{C}$ IJs swapped at day 0}

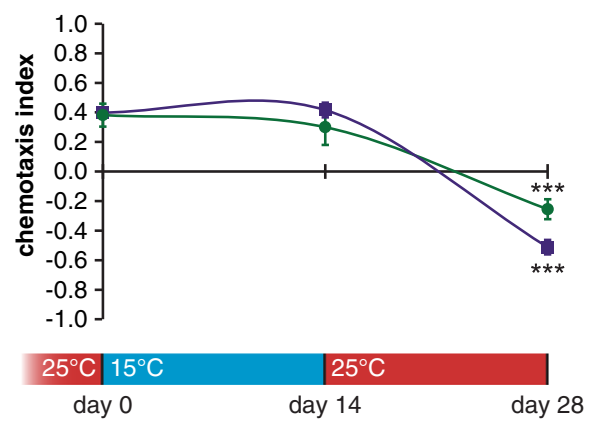

d $25^{\circ} \mathrm{C}$ IJs maintained at $25^{\circ} \mathrm{C}$

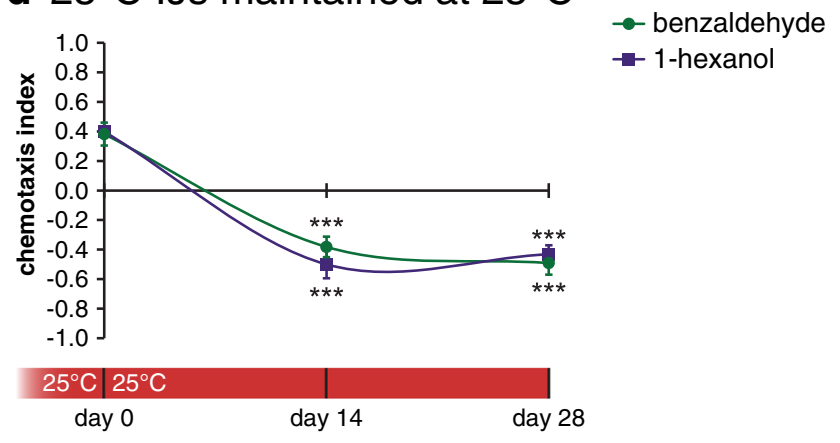

Fig. 4 Heterorhabditis bacteriophora exhibits age-dependent changes in olfactory behavior. a Infective juveniles (IJS) were grown at $25^{\circ} \mathrm{C}$ and temperature-swapped to $15^{\circ} \mathrm{C}$ on day 0 . The olfactory responses of temperature-swapped day $28 \mathrm{IJs}$ but not day 14 IJs were significantly different from those of $25^{\circ} \mathrm{C}$ day $0 \mathrm{IJS}$ for all odorants except methyl salicylate and $\mathrm{CO}_{2}{ }^{*} P<0.05$; ${ }^{* * *} \mathrm{P}<0.001$ relative to day $0 \mathrm{IJS}$; two-way ANOVA with Dunnett's post-test; $n=6-8$ trials for each condition. $\mathbf{b}$ IJs were grown and maintained at $25^{\circ} \mathrm{C}$. Olfactory responses to all odorants except $\mathrm{CO}_{2}$ changed as a function of parasite age. ${ }^{*} P<0.05 ;{ }^{* *} P<0.01 ;{ }^{* *} P<0.001$ relative to day $0 \mathrm{IJs}$; two-way ANOVA with Dunnett's post-test; $n=6-8$ trials for each condition. $\mathbf{c}$, $\mathbf{d}$ IJs were grown at $25^{\circ} \mathrm{C}$ and either temperature-swapped to $15^{\circ} \mathrm{C}$ and back to $25^{\circ} \mathrm{C}$ (c) or maintained at $25^{\circ} \mathrm{C}$ (d). IJs were then tested for their responses to benzaldehyde and 1-hexanol, which showed the largest valence change in (b). In both conditions, IJs switched their odorant response from attraction to repulsion over time, consistent with an age-dependent effect. ${ }^{* * *} P<0.001$ relative to day 0 IJs; two-way ANOVA with Dunnett's post-test; $n=8$ trials for each condition. For all graphs, error bars represent standard error of the mean (SEM). Mean, $n$, and SEM values for each assay are listed in Additional file 7: Dataset S1

therefore wondered whether the $\mathrm{CO}_{2}$ response of Ste. scapterisci might vary with cultivation temperature or parasite age.

We first looked at Ste. scapterisci IJs that were aged for several months at either $15{ }^{\circ} \mathrm{C}$ or $25{ }^{\circ} \mathrm{C}$. We found that, in both cases, old IJs showed strong attraction to $\mathrm{CO}_{2}$ as well as potential insect hosts, including its natural host, the mole cricket Scapteriscus borellii (Fig. 5a). These results corroborated our previous findings and indicated that Ste. scapterisci changes the valence of its 


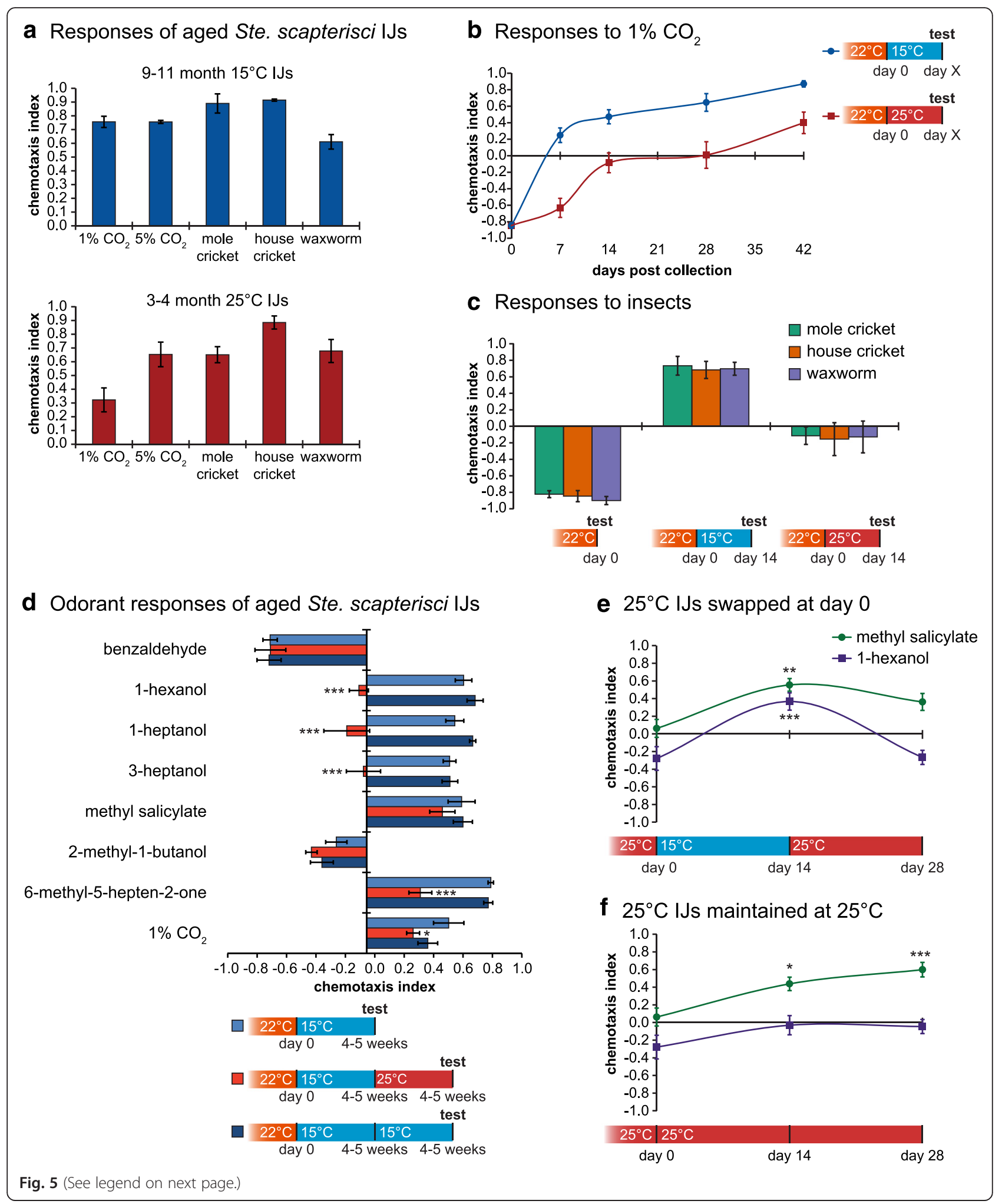


(See figure on previous page.)

Fig. 5 Steinernema scapterisci shows temperature- and age-dependent changes in response to odorants, $\mathrm{CO}_{2}$, and host odor. a Infective juveniles (IJs) incubated at $15{ }^{\circ} \mathrm{C}$ or $25^{\circ} \mathrm{C}$ for several months showed attraction to $\mathrm{CO}_{2}$ and insects. $n=4-8$ trials for each condition. $\mathbf{b} \mathrm{IJs}$ were grown at room temperature $\left(22^{\circ} \mathrm{C} \pm 1{ }^{\circ} \mathrm{C}\right)$ and incubated at either $15^{\circ} \mathrm{C}$ or $25^{\circ} \mathrm{C}$. For both temperature treatments, IJs showed a gradual shift in their $\mathrm{CO}_{2}$ response from repulsive to attractive with increasing age; $n=8-16$ trials for each condition. $\mathbf{c}$ IJs showed a shift in their responses to potential insect hosts that corresponded with their changing response to $\mathrm{CO}_{2} ; n=6-8$ trials for each condition. $\mathbf{d}$ IJs were grown at room temperature $\left(22^{\circ} \mathrm{C} \pm 1{ }^{\circ} \mathrm{C}\right.$ ) and incubated at $15^{\circ} \mathrm{C}$ for $4-5$ weeks until their responses to $\mathrm{CO}_{2}$ shifted to attraction. IJs were then swapped to $25^{\circ} \mathrm{C}$ or maintained at $15^{\circ} \mathrm{C}$ for another $4-5$ weeks. The responses of IJs to several of the tested odorants differed as a function of temperature, suggesting olfactory plasticity occurs independently of the change in $\mathrm{CO}_{2}$ response valence. ${ }^{*} P<0.05$; ${ }^{* *} P<0.001$ relative to the initial $4-5$ week IJ population; two-way ANOVA with Dunnett's post-test; $n=6$ trials for each condition. e, $\mathbf{f} \mathrm{IJs}$ were grown at $25^{\circ} \mathrm{C}$ and either temperature-swapped to $15^{\circ} \mathrm{C}$ and back to $25^{\circ} \mathrm{C}(\mathbf{e})$ or maintained at $25^{\circ} \mathrm{C}(\mathbf{f})$ and tested for their responses to two selected odorants. Responses to these odorants changed as a function of age and/or temperature. ${ }^{*} P<0.05 ;{ }^{* *} P<0.01$; ** $P<0.001$ relative to day $0 \mathrm{IJs}$; two-way ANOVA with Dunnett's post-test; $n=8$ trials for each condition. For all graphs, error bars represent standard error of the mean (SEM). Mean, $n$, and SEM values for each assay are listed in Additional file 7: Dataset S1

$\mathrm{CO}_{2}$ response over time. To investigate how quickly this change occurs, we took room temperature-grown Ste. scapterisci IJs, cultivated them at $15{ }^{\circ} \mathrm{C}$ or $25{ }^{\circ} \mathrm{C}$, and measured their response to $1 \% \mathrm{CO}_{2}$ over the course of 6 weeks (Fig. 5b). We found that, while there was a temperature-dependent difference in the rate at which the responses changed, both IJs maintained at $15{ }^{\circ} \mathrm{C}$ and those maintained at $25{ }^{\circ} \mathrm{C}$ gradually shifted their $\mathrm{CO}_{2}$ response from repulsion to attraction. Furthermore, this change in $\mathrm{CO}_{2}$ response correlated with a change in their response to insect hosts (Fig. 5c). Taken together, these data suggest that Ste. scapterisci changes its response to both $\mathrm{CO}_{2}$ and insect hosts in an agedependent manner.

We next asked whether temperature-induced changes in olfactory behavior occurred independently of the age-dependent changes in $\mathrm{CO}_{2}$ response. To address this, we cultivated IJs at $15{ }^{\circ} \mathrm{C}$ for $4-5$ weeks until they became attracted to $\mathrm{CO}_{2}$ and then measured their responses to our selected eight-odorant panel (Fig. 5d). We then temperature-swapped these IJs to $25{ }^{\circ} \mathrm{C}$ or maintained them at $15{ }^{\circ} \mathrm{C}$ for another $4-5$ weeks. The aged worms, which were consistently attracted to $\mathrm{CO}_{2}$, showed significant temperature-dependent changes in olfactory behavior. We also tested $25{ }^{\circ} \mathrm{C}$ IJs that were either swapped to $15{ }^{\circ} \mathrm{C}$ and then back to $25{ }^{\circ} \mathrm{C}$, or maintained at $25{ }^{\circ} \mathrm{C}$, in response to two odorants that were selected based on their mode of valence change (Fig. 5e, f). Methyl salicylate showed a predominantly age-dependent change, whereas 1-hexanol showed a temperature-dependent change. Taken together, these data suggest that Ste. scapterisci IJs exhibit dramatic changes in olfactory behavior in response to both temperature and age.

\section{Cultivation temperature alters parasite host-seeking strategy}

In addition to odor-driven behavior, another critical aspect of host finding is host-seeking strategy. We therefore asked whether host-seeking strategy is also modulated by cultivation temperature using Ste. carpocapsae, a species classically categorized as an ambusher [32]. We first examined the motility of 2- to 3-week-old IJs that were either cultured at $25{ }^{\circ} \mathrm{C}$, or cultured at $25{ }^{\circ} \mathrm{C}$ and temperature-swapped to $15{ }^{\circ} \mathrm{C}$ immediately after emergence from the host. Using automated worm tracking [30], we found that both sets of IJs showed similar average crawling speeds (Fig. 6a). We then examined nictation, an ambushing behavior in which the IJ stands on its tail and waves its head to facilitate host attachment [32]. Nictation was assayed on "micro-dirt" chips containing near-microscopic raised agar pillars as an artificial dirt substrate [54], since IJs cannot nictate on standard agar plates due to the high surface tension on the plate. We found that IJs maintained at $25{ }^{\circ} \mathrm{C}$ had a greater propensity to nictate than IJs temperature-swapped from $25{ }^{\circ} \mathrm{C}$ to $15{ }^{\circ} \mathrm{C}$ (Fig. 6b). These results suggest that host-seeking strategy is temperature-dependent, with Ste. carpocapsae behaving more like an ambusher at higher temperatures and more like a cruiser at lower temperatures.

The fact that Ste. carpocapsae IJs showed a greater tendency to ambush at warmer temperatures raised the question of whether they remained attracted to hostemitted odorants under these conditions. Previous studies demonstrated chemotaxis of Ste. carpocapsae IJs to host-emitted odorants at room temperature on flat agar surfaces [22, 23]; however, IJs were not capable of nictating under these assay conditions. To test whether Ste. carpocapsae IJs chemotax toward host-emitted odorants at warm temperatures when given a choice between nictating and crawling, we examined IJ behavior in a $\mathrm{CO}_{2}$ gradient on micro-dirt chips. We found that both IJs maintained at $25{ }^{\circ} \mathrm{C}$ and IJs temperature-swapped from $25{ }^{\circ} \mathrm{C}$ to $15{ }^{\circ} \mathrm{C}$ displayed equally robust chemotaxis toward $\mathrm{CO}_{2}$ (Fig. 6c). Thus, although warm-temperature IJs nictated more than cold-temperature IJs in the absence of a host stimulus, both warm- and coldtemperature IJs migrated toward a host stimulus to similar extents. These results suggest that Ste. carpocapsae IJs display cruising behavior at lower temperatures, and a combination of cruising and ambushing behavior at 
a Average crawling speed

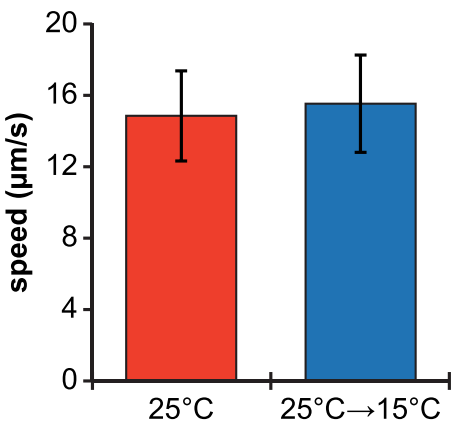

b Host-seeking strategy

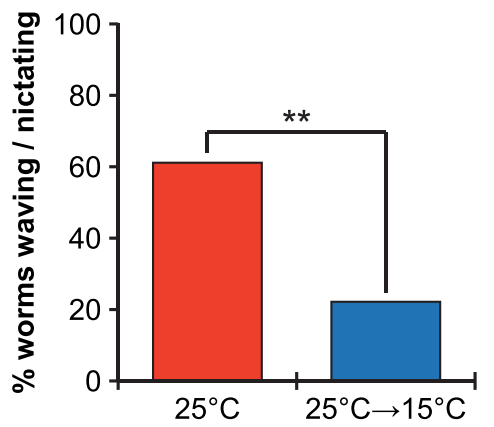

c $\mathrm{CO}_{2}$ chemotaxis on artificial dirt

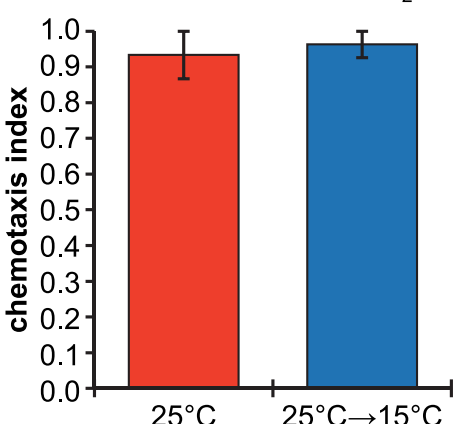

movement toward $\mathrm{CO}_{2}$

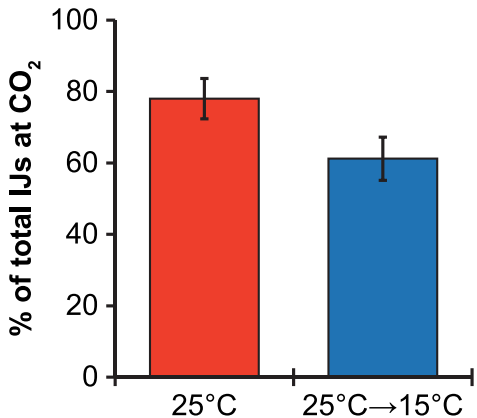

test

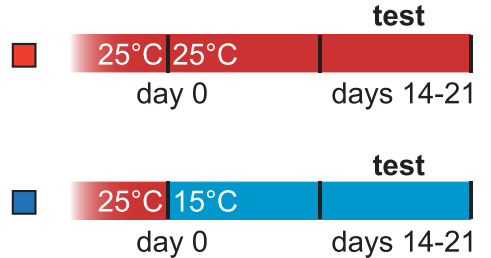

Fig. 6 Steinernema carpocapsae exhibits temperature-induced changes in host-seeking strategy. a Temperature changes did not affect the crawling speeds of infective juveniles (IJs). The crawling speeds of day $14-21 \mathrm{IJs}$ that were either maintained at $25^{\circ} \mathrm{C}$, or temperature-swapped from $25^{\circ} \mathrm{C}$ to $15^{\circ} \mathrm{C}$ on day 0 , were not significantly different (Mann-Whitney test); $n=26-31 \mathrm{IJs}$ for each condition. $\mathbf{b}$ Temperature changes altered the host-seeking strategies of IJs. Day $14-21 \mathrm{IJS}$ that were maintained at $25^{\circ} \mathrm{C}$ showed a greater propensity to nictate than IJs that were temperature-swapped from $25^{\circ} \mathrm{C}$ to $15^{\circ} \mathrm{C}$ on day $0 . * * P<0.01$; Fisher's exact test; $n=36 \mathrm{IJs}$ for each condition. $\mathbf{c}$ Temperature changes did not alter $\mathrm{CO}_{2}$ chemotaxis behavior. $\mathrm{CO}_{2}$ attraction for IJs that were either maintained at $25^{\circ} \mathrm{C}$, or temperature-swapped from $25^{\circ} \mathrm{C}$ to $15^{\circ} \mathrm{C}$ on day 0 , was not significantly different (left graph, unpaired $t$-test). In addition, the percentage of the population that migrated toward the $\mathrm{CO}_{2}$ was not significantly different for the two treatment conditions (right graph, unpaired $t$-test); $n=6-8$ trials for each condition. For all graphs, error bars represent standard error of the mean (SEM). Mean, $n$, and SEM values for each assay are listed in Additional file 7: Dataset S1

higher temperatures. A flexible switch in foraging behavior, combined with changes in olfactory behavior, may allow these IJs to optimize host-seeking under changing environmental conditions.

Temperature-dependent olfactory plasticity also occurs in mammalian-parasitic nematodes

We next asked if temperature-dependent changes in olfactory behavior occur in other types of parasitic nematodes. To address this question, we turned to another parasitic nematode that engages in active host seeking, the skin-penetrating rat parasite Strongyloides ratti. Str. ratti is a close relative of the human threadworm Strongyloides stercoralis, a parasite estimated to infect up to 100 million humans worldwide [55]. We selected a 16odorant panel of mammalian-derived odorants, many of which were previously identified as attractants for Str. ratti or Str. stercoralis [30,56], and examined the effect of cultivation temperature on Str. ratti olfactory behavior. We found that IJs temperature-swapped from $23{ }^{\circ} \mathrm{C}$ to $15{ }^{\circ} \mathrm{C}$ showed significant differences in their responses to several odorants compared to IJs maintained at $23{ }^{\circ} \mathrm{C}$ 


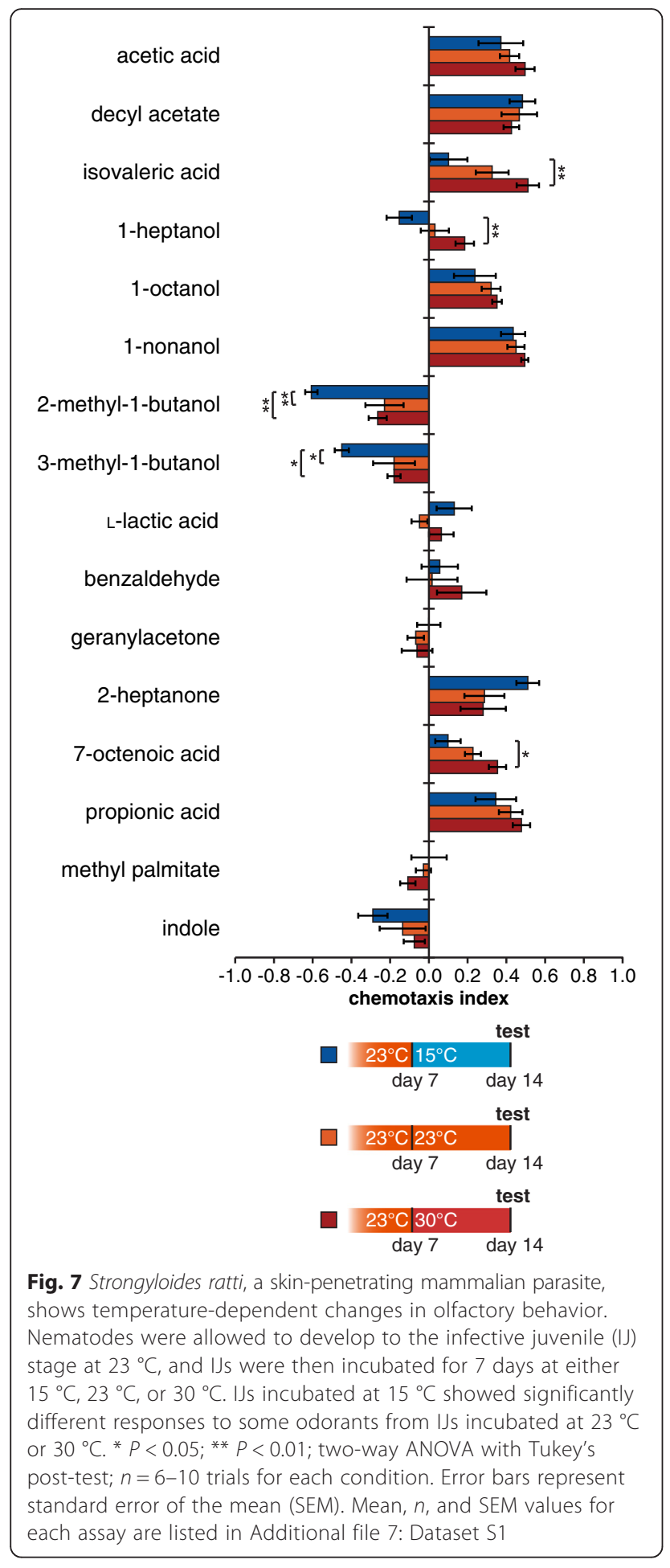

or temperature-swapped from $23{ }^{\circ} \mathrm{C}$ to $30{ }^{\circ} \mathrm{C}$ (Fig. 7). In particular, isovaleric acid and 7-octenoic acid elicited attractive responses for IJs cultivated at $30{ }^{\circ} \mathrm{C}$ but neutral responses for those cultivated at $15{ }^{\circ} \mathrm{C}$. Thus, like EPNs, skin-penetrating nematodes exhibit temperature-dependent olfactory plasticity. Str. ratti has been reported to show seasonal prevalence in wild rats [57], raising the possibility that temperature-dependent changes in olfactory behavior could contribute to seasonal cycles of infectivity.

\section{Discussion}

Our results demonstrate that parasitic nematodes modulate their olfactory preferences and host-seeking strategy in response to changing external cues such as temperature and internal cues such as age. Environmental temperature and age have been shown to modulate olfactory sensitivity or discrimination in a number of free-living animals. For example, Oriental fruit moths show a decreased ability to discriminate among pheromone blends at higher temperatures [58], and aged Caenorhabditis elegans adults show decreased attraction to benzaldehyde [59]. Temperature also modulates olfactory discrimination in turtles [60, 61], olfactory sensitivity in the fruit fly Drosophila melanogaster [62, 63], and $\mathrm{CO}_{2}$ sensitivity in C. elegans adults [64]. However, the robust, long-lasting temperatureinduced olfactory valence changes that occur in parasitic nematodes have not been previously reported.

The finding that temperature-dependent changes in IJ olfactory behavior occur over a period of several days to weeks suggests that these changes are reflective of a seasonal adaptation. EPNs inhabit a broad range of geographic habitats, many of which are subject to seasonal temperature variation [10], and persist in the soil throughout the year [65-67]. In changing seasonal conditions, temperature-dependent olfactory plasticity may allow EPNs to modulate or optimize their host seeking by altering host preferences, enabling EPNs to target seasonally prevalent hosts or host life stages. Most EPNs are capable of parasitizing a wide variety of insect pests [11, 68], many of which show seasonal variation in their prevalence or the prevalence of particular life stages [69-71]. For example, the Western corn rootworm Diabrotica virgifera virgifera and the bluegrass billbug Sphenophorus parvulus are known hosts for Ste. carpocapsae $[14,72]$ and both have seasonal life cycles [73, 74 ]. Olfactory plasticity may also allow EPNs to migrate toward seasonal plants that insect hosts infest, since several of the odorants that were subject to temperaturedependent changes, including benzaldehyde, 1-hexanol, 1hexanal, and methyl salicylate, are emitted by plants as well as insects [75]. Furthermore, volatiles emitted from plants vary depending on temperature or season [76, 77]. Thus, temperature-induced changes in host-seeking strategy could allow EPNs to compensate for temperatureinduced changes in insect movement or habitat, or to target both mobile and sedentary hosts or host life stages.

In contrast to the other parasite species tested, Ste. scapterisci and Str. ratti have very specific host ranges $[51,78,79]$. Olfactory plasticity in these parasites may 
instead reflect an adaptation to changing host volatile emissions. Both mammals and insects show variations in their volatile emissions as a result of seasonal changes in photoperiod or hormonal levels [80-84]. Thus, temperature-dependent olfactory plasticity may allow parasites with specific host ranges to locate and infect preferred hosts under changing environmental conditions. We note that fewer temperature-dependent changes in olfactory behavior were observed with Str. ratti than with some of the EPN species (Fig. 7 and Additional file 6: Figure S6). In future studies, it will be interesting to test whether other mammalian-parasitic species show more extreme temperature-dependent changes in olfactory behavior, or whether extreme temperature-dependent olfactory plasticity is limited to some EPNs.

Ste. scapterisci differed from the other EPNs tested in that its response to $\mathrm{CO}_{2}$ changed with IJ age - young IJs were repelled by $\mathrm{CO}_{2}$, while older IJs were attracted to it (Fig. 5). The changes in $\mathrm{CO}_{2}$ response paralleled changes in the response to host odor, including the odor of its natural host, the mole cricket (Fig. 5). Thus, the response to $\mathrm{CO}_{2}$ may be driving the response to hosts. The repulsion of young IJs from $\mathrm{CO}_{2}$ and host odor may function as a dispersal mechanism, causing the young IJs to migrate out into the environment rather than remain in the vicinity of already utilized host niches. Long-range dispersal mechanisms may be particularly important for Ste. scapterisci due to the faster speed of crickets relative to the insect larvae targeted by most EPNs. Another possibility is that young Ste. scapterisci IJs may be riskaverse, as has been proposed for other Steinernema species $[85,86]$. Mole crickets are refractory to infection, even by Ste. scapterisci [23], and it may be that only as the IJs age and lose energy resources are they likely to attempt infecting a mole cricket.

While we have found that long-lasting changes in olfactory behavior occur in several parasitic nematode IJs, it remains unknown whether the analogous dauer stage of free-living nematodes exhibits olfactory plasticity. Previous studies investigating $C$. elegans and the beetleassociated necromenic nematode Pristionchus pacificus and age- or temperature-dependent changes in olfactory behavior have looked at adults but not dauers [42, 59, 87, 88]. Like parasitic nematode IJs, C. elegans dauers exhibit robust chemotaxis toward odorants [22, 30]; the chemotaxis behaviors of the dauers of other free-living species have not yet been examined in depth. P. pacificus live in close association with beetles and engage in active host-seeking [87], while C. elegans dauers show phoretic associations that appear to be relatively non-specific [89]. In future studies, it will be interesting to determine whether these species also show context-dependent changes in host-seeking behaviors.
Although EPNs are generally categorized as either ambushers or cruisers [11,90], a number of recent studies suggest that the traditional ambusher/cruiser distinction may be an oversimplification. For example, the classical ambusher Ste. carpocapsae is effective at controlling a number of immobile insect pests, including large pine weevil larvae and codling moth larvae, suggesting it can employ a cruising strategy to target immobile hosts [91]. Ste. carpocapsae also disperses more in some types of soil than others, suggesting that host-seeking strategy is substrate-dependent [91]. Our results demonstrate that host-seeking strategy is also regulated by temperature, with warmer temperatures stimulating ambushing and colder temperatures stimulating cruising (Fig. 6b). However, even warm-temperature IJs crawl toward the source of an odorant (Fig. 6c), demonstrating that the decision to ambush or cruise depends on both temperature and the presence of host-emitted sensory cues. Our results argue against the simple ambusher/ cruiser distinction and suggest that host-seeking strategy is context-dependent.

The cellular mechanisms that underlie olfactory plasticity in parasitic nematodes remain obscure, as remarkably little is known about the mechanisms of olfaction in parasitic nematodes. The only olfactory neurons that have so far been identified in parasitic nematodes are the $\mathrm{CO}_{2}$-sensing BAG neurons [22]. However, since nematode neuroanatomy and function are often conserved across species [21], the positional analogs of the C. elegans olfactory neurons are likely to function as olfactory neurons in parasitic nematodes. In C. elegans, the AWC olfactory neurons are also thermosensitive $[92,93]$. Thus, if olfactory neuron function is similar in parasitic nematodes, the integration of olfactory and thermosensory cues may occur at the level of the primary sensory neurons. The molecular mechanisms that mediate olfactory plasticity in parasitic nematodes also remain to be elucidated. However, we note that temperature-dependent changes in development or metabolism are unlikely to account for olfactory plasticity since the observed changes in olfactory behavior are reversible, occur gradually over the course of days to weeks following a temperature swap, and occur more slowly in older IJs (Fig. 3).

In addition to responding to olfactory and thermosensory stimuli, parasitic nematodes respond to other sensory modalities such as electric fields [94, 95], magnetic fields [96], and vibration [97, 98]. These sensory modalities have been proposed to play a role in host seeking [94-98], and in future studies it will be interesting to test whether they are subject to context-dependent plasticity. In addition, in the case of EPNs, IJ populations exhibit behavioral heterogeneity. For example, dispersal behavior varies among 
individuals and depends on the time of emergence from the insect host [99]. Host-invasion behavior also varies among individuals such that some IJs invade new hosts more readily than others [85]. Thus, physiological cues other than age also regulate host seeking. The nature of these cues and how they are integrated with temperature, age, and olfactory environment remain to be investigated.

\section{Conclusions}

Our results uncover a surprising behavioral plasticity in EPNs that is likely to influence their efficacy for insect biocontrol. Future studies of the relationship between temperature, parasite age, and field efficacy may improve the utility of EPNs for biocontrol. In addition, our finding that skin-penetrating nematodes exhibit similar behavioral plasticity raises the possibility that contextdependent behavioral changes are widespread among parasitic nematodes. Parasitic nematodes of humans cause some of the most common neglected tropical diseases, particularly in low resource areas, while parasitic nematodes of livestock and plants are a major cause of economic and food loss worldwide [45, 100]. A better understanding of behavioral plasticity in these parasites could facilitate the development of new strategies for preventing harmful infections.

\section{Methods}

\section{Nematodes}

EPN strains were as follows: Ste. carpocapsae All [22, 23] (except for DD136 and Sal [101] in Additional file 4: Figure S4C); H. bacteriophora M31e [22, 23]; Ste. scapterisci FL [23]; Ste. riobrave TX [23]; Ste. feltiae SN [102, 103]; and $H$. indica Hom 1 [103]. All strains were from our laboratories except for Ste. carpocapsae DD136, Ste. carpocapsae Sal, and $H$. indica Hom1, which were generously provided by David Shapiro-Ilan, USDA.

\section{Nematode culturing}

For all EPNs except Ste. scapterisci, 3-6 last-instar Galleria mellonella larvae (purchased commercially) were placed in a 5-cm Petri dish lined with a 55-mm Whatman 1 filter paper; $250 \mu \mathrm{L}$ of $\mathrm{ddH}_{2} \mathrm{O}$ containing 1000-2000 IJs was distributed evenly on the filter paper. The Petri dishes were placed at $15{ }^{\circ} \mathrm{C}, 20{ }^{\circ} \mathrm{C}$, room temperature $\left(22{ }^{\circ} \mathrm{C} \pm 1^{\circ}\right.$ $\mathrm{C})$, or $25^{\circ} \mathrm{C}$ for $9-11$ days $\left(20^{\circ} \mathrm{C}\right.$, room temperature, or $25^{\circ}$ C) or $20-22$ days $\left(15^{\circ} \mathrm{C}\right)$ and then placed on White traps [104]. IJs were collected after 3-4 days $\left(20{ }^{\circ} \mathrm{C}\right.$, room temperature, or $\left.25{ }^{\circ} \mathrm{C}\right)$ or $4-6$ days $\left(15{ }^{\circ} \mathrm{C}\right)$ and rinsed three times in $\mathrm{dd}_{2} \mathrm{O}$. The day of collection was considered day 0 . IJs were stored at $15{ }^{\circ} \mathrm{C}, 20{ }^{\circ} \mathrm{C}$, room

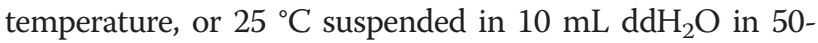
$\mathrm{mL}$ tissue culture flasks unless otherwise indicated.

For Ste. scapterisci, adult Acheta domesticus house crickets (purchased commercially) were placed individually in 5-cm Petri dishes lined with a 55-mm Whatman 1 filter paper; $250 \mu \mathrm{L}$ of $\mathrm{dd}_{2} \mathrm{O}$ containing $\sim 250-1000$ IJs was distributed evenly on the filter paper. The Petri dishes were placed at room temperature or in $25^{\circ} \mathrm{C}$ incubators for 4-13 days and then placed on White traps. IJs were collected after 3-11 days and rinsed three times in $\mathrm{ddH}_{2} \mathrm{O}$. The day of the collection was considered day 0. Populations were collected within 4 days of IJ formation and emergence. IJs were stored at $15{ }^{\circ} \mathrm{C}$ or

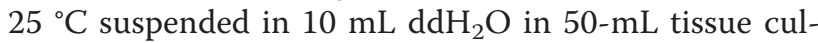
ture flasks.

Str. ratti was cultured essentially as previously described [30]. Briefly, rats were subcutaneously inoculated with $\sim 800 \mathrm{IJs}$ in $300 \mu \mathrm{L}$ sterile PBS. Fecal pellets containing nematode eggs were collected from patent rats. Fecal-charcoal plates were prepared by mixing the fecal pellets with $\mathrm{dH}_{2} \mathrm{O}$ and autoclaved charcoal (bone char, Ebonex) in an approximately 1:1 ratio of feces to charcoal. The mix was poured into Petri dishes $(100 \mathrm{~mm}$ by $20 \mathrm{~mm}$ ) lined with wet $90 \mathrm{~mm}$ Whatman 1 filter paper and stored at $23{ }^{\circ} \mathrm{C}$ until use. IJs were isolated from fecal-charcoal plates using a Baermann apparatus [105] after 7 days. IJs were then rinsed three times in $\mathrm{dH}_{2} \mathrm{O}$ and stored in $\sim 7.5 \mathrm{~mL}$ BU saline [105] in 50-mL tissue culture flasks at $15{ }^{\circ} \mathrm{C}, 23{ }^{\circ} \mathrm{C}$, or $30{ }^{\circ} \mathrm{C}$ for 7 days before use. Protocols and procedures for the host passage of Str. ratti in rats were approved by the UCLA Office of Animal Research Oversight (Protocol No. 2011-060$12 \mathrm{C})$, which adheres to the AAALAC standards for laboratory animal use, and were in strict accordance with the Guide for the Care and Use of Laboratory Animals.

For temperature-swap experiments, nematodes were cultured at room temperature or $25{ }^{\circ} \mathrm{C}$ as indicated. IJs were then split into the different temperature populations $\left(15^{\circ} \mathrm{C}\right.$ or $25{ }^{\circ} \mathrm{C}$ for EPNs; $15{ }^{\circ} \mathrm{C}, 23^{\circ} \mathrm{C}$, or $30^{\circ} \mathrm{C}$ for Str. ratti).

\section{Chemotaxis assays}

Odorant, host, and $\mathrm{CO}_{2}$ chemotaxis assays were performed as previously described [22, 23, 30]. Assays were performed on chemotaxis assay plates [106]. The assay setup is shown in Additional file 1: Figure S1. For odorant chemotaxis assays, $1 \mu \mathrm{L}$ (for EPNs) or $2 \mu \mathrm{L}$ (for Str. ratti) of $5 \%$ sodium azide was placed in the center of each scoring region as an anesthetic; $5 \mu \mathrm{L}$ of odorant (Sigma-Aldrich or Fisher) was placed in the center of one scoring region and $5 \mu \mathrm{L}$ of a control (paraffin oil or $\mathrm{ddH}_{2} \mathrm{O}$ ) was placed in the center of the other scoring region. Liquid odorants were tested undiluted unless otherwise noted. Solid odorants were dissolved as follows: $p$-cresol and methyl palmitate, $0.05 \mathrm{~g}$ in $2.5 \mathrm{~mL}$ paraffin oil; dimethyl sulfone and 3-hydroxy-2-butanone, $1 \mathrm{~g}$ in $4 \mathrm{~mL} \mathrm{ddH}_{2} \mathrm{O}$; L-lactic acid, $0.05 \mathrm{~g}$ in

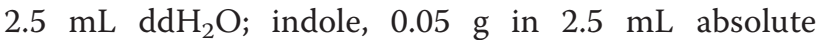


ethanol. Trimethylamine was purchased as a 45 wt. \% in $\mathrm{H}_{2} \mathrm{O}$ (Sigma-Aldrich). For the dose-response curves in Additional file 3: Figure S3B, 1-hexanol was diluted in paraffin oil and 2-propanone in $\mathrm{dd}_{2} \mathrm{O}$. The odor blends in Additional file 3: Figure S3C were created as follows: Mix 1: $10^{-1}$ dilutions of methyl acetate, 1propanol, and 2-propanone in $\mathrm{ddH}_{2} \mathrm{O}$; Mix 2: $10^{-1}$ dilutions of 1-hexanol, 6-methyl-5-hepten-2-one, and methyl salicylate in paraffin oil; Mix 3:10 $0^{-1}$ dilutions of 1-hexanol, 7-octenoic acid, and 2,2,4-trimethylpentane in paraffin oil. For $\mathrm{CO}_{2}$ chemotaxis assays, $50 \mathrm{~mL}$ gastight syringes were filled with a certified mixture containing $1 \% \mathrm{CO}_{2}$ or $0 \%$ $\mathrm{CO}_{2}$ (control syringe) in a $10 \%$ oxygen $\left(\mathrm{O}_{2}\right)$ or $21 \% \mathrm{O}_{2}$, balance nitrogen background. For host chemotaxis assays, one adult mole cricket (Scapteriscus borellii, collected from the wild as previously described [23, 107]), four adult house crickets, or six waxworms were placed in a $50-\mathrm{mL}$ gastight syringe and tested against a control syringe filled with room air. Syringes were depressed using a syringe pump initially at a rate of $5 \mathrm{~mL} / \mathrm{min}$ for at least 1 minute to flush the tubing, then at a rate of $0.5 \mathrm{~mL} / \mathrm{min}$ for the duration of the assay. Gases were delivered to opposite sides of the assay plate through holes drilled into the plate lids directly above the centers of the scoring regions.

For each trial, $2-3 \mu \mathrm{L}$ of worm pellet containing 100-500 nematodes was washed three times with $\mathrm{ddH}_{2} \mathrm{O}$ and placed in the center of the assay plate. Assay plates were left undisturbed on a vibrationreducing platform and were scored after 1 hour for $\mathrm{CO}_{2}$ and host assays or 3 hours for odor assays. A chemotaxis index $(\mathrm{CI})$ was calculated as $\mathrm{CI}=$ (number of worms in odorant or $\mathrm{CO}_{2}$ circle - number of worms in control circle)/(number of worms in both circles) (Additional file 1: Figure S1). Trials were always done in pairs, and were only counted if more than seven worms moved into the scoring region for both trials and if the CI difference between the two trials was less than one to account for directional bias due to room vibration. For all chemotaxis assays, at least two replicates of trial pairs were performed using separate batches of worms on different days to account for batch-to-batch and day-to-day variability. All chemotaxis assays except those in Additional file 2: Figure S2B, C were conducted at room temperature; thus, we examined the effects of cultivation temperature rather than current ambient temperature on olfactory preferences.

For the assay temperature controls in Additional file 2: Figure S2B, C, sodium azide and paraffin oil were applied to chemotaxis plates as above and kept at the assay temperature $\left(15{ }^{\circ} \mathrm{C}\right.$, room temperature, or $\left.25{ }^{\circ} \mathrm{C}\right)$ for at least 1 hour; $15{ }^{\circ} \mathrm{C}$ or $25^{\circ} \mathrm{C}$ IJs were washed three times

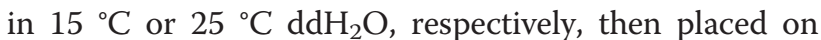
the pre-incubated chemotaxis plates along with $15{ }^{\circ} \mathrm{C}$ or $25{ }^{\circ} \mathrm{C}$ odorant. Throughout the set-up, pre-incubated reagent and IJ exposure to room temperature was minimized and kept to under 5 minutes. Assays were then conducted at room temperature as described above or in $15{ }^{\circ} \mathrm{C}$ or $25^{\circ} \mathrm{C}$ incubators.

For the experiment shown in Additional file 4: Figure S4A, where the same IJs were tested under multiple conditions, $25^{\circ} \mathrm{C}$ day 0 Ste. carpocapsae IJs were tested for their response to 2-propanone by using a modified chemotaxis "lid" assay in which the odorant and control were placed on a small piece of Whatman 1 filter paper affixed above the scoring region [30]. No sodium azide was used. After 3 hours, IJs initially repelled by 2 propanone were removed from the one-third plate region at the control side of the plate. Recovered IJs were stored at either $15{ }^{\circ} \mathrm{C}$ or $25^{\circ} \mathrm{C}$ in 96 -well plates in $50 \mu \mathrm{L}$ of $\mathrm{ddH}_{2} \mathrm{O}$ for 2 weeks before re-testing their response to 2-propanone in a chemotaxis assay where the scoring regions were modified as illustrated to calculate a response index (Additional file 4: Figure S4A).

\section{Automated worm tracking}

Automated worm tracking was performed essentially as previously described [30]. Briefly, 5-10 IJs from three replicate batches were placed on a chemotaxis plate and allowed to acclimate to room temperature for 1 hour. To measure average speed, IJ movement was recorded using an Olympus E-PM1 digital camera attached to a Leica S6 D microscope for $60 \mathrm{~s}$. Recordings were analyzed using WormTracker and WormAnalyzer software (Miriam Goodman lab, Stanford University) [108]. Analysis was conducted as previously described [30], except that the following WormTracker settings were adjusted: sample rate $=15$ frames $/ \mathrm{s}$; auto-thresholding correction factor $=0.20$. The average speed of IJs that did not move during the assay period but were confirmed to be alive at the end of the assay was manually zeroed. We note that one Ste. carpocapsae IJ in the $25{ }^{\circ} \mathrm{C}$ to $15{ }^{\circ} \mathrm{C}$ temperature-swapped population crawled at a speed that was approximately 10 times faster than that of the other IJs tested, suggesting it was a "sprinter" [109]. Sprinters, which comprise less than $5 \%$ of the IJ population, disperse farther than other IJs and are thought to facilitate long-range population dispersal in the absence of a host [109]. This IJ was not included in our population analysis.

\section{Nictation assay}

Assays were conducted on $\sim 3 \times 3.5 \mathrm{~cm}$ "micro-dirt" agar chips cast from polydimethylsiloxane (PDMS) molds as previously described [54]. Micro-dirt chips were made by pouring $4 \%$ agar dissolved in $\mathrm{dd}_{2} \mathrm{O}$ onto a PDMS mold containing arrays of near-microscopic posts ( $25 \mu \mathrm{m}$ post height, $25 \mu \mathrm{m}$ post radius, $25 \mu \mathrm{m}$ distance between posts). Chips were dried at $37^{\circ} \mathrm{C}$ for 2 hours before use. IJs were allowed to acclimate to room 
temperature for $\sim 30$ minutes before $\sim 5$ IJs from 5-6 replicate batches were transferred onto a chip. IJs were allowed to acclimate to the chip for 20-30 minutes. IJs were then assayed for waving or nictation behavior, as defined by the lifting of at least $30 \%$ of the anterior of their body, during a $60 \mathrm{~s}$ period. IJs were counted as "nictating" if they were waving or nictating for a span of at least $5 \mathrm{~s}$ during the assay period.

\section{$\mathrm{CO}_{2}$ chemotaxis assay on micro-dirt agar chips}

$\mathrm{CO}_{2}$ assays were as described above, except that they were conducted on $8 \times 4 \mathrm{~cm}$ micro-dirt chips. IJs $(n=$ 10-15) were allowed to acclimate to room temperature for 1 hour and then placed at the center of the chip and tested for their response to $10 \% \mathrm{CO}_{2}$. A modified scoring method was used in which the plate was divided into three equidistant regions along the diameter of the plate; IJs were counted as responding if they were found in the one-third of the chip under the $\mathrm{CO}_{2}$ flow.

\section{Statistical analysis}

Statistical analysis was performed using GraphPad Prism 6.04. Standard statistical tests were used for all experiments, as described in the figure legends. For most figures, two-way ANOVAs were conducted, testing the effects of odorant and temperature/age. Multiple comparison post-tests were conducted if the interaction or temperature/age effect was significant. For all population assays, the value for sample size $(n)$ refers to the number of trials performed for each condition. For Fig. 6b, because individual worms were monitored, responses were compiled in a contingency table and analyzed using Fisher's exact test.

\section{Availability of data and materials}

Mean, $n$, and standard error of the mean values for each assay are listed in Additional file 7: Dataset S1.

\section{Additional files}

Additional file 1: Figure S1. Chemotaxis assay for infective juveniles (IJs). Odorants were placed on one side of the plate and controls were placed on the other side (black dots). IJs were placed in the center of the plate and allowed to migrate in the odorant gradient for 3 hours. A chemotaxis index was then calculated as indicated. The chemotaxis index ranges from +1 (most attractive) to -1 (most repulsive). Red bar $=1 \mathrm{~cm}$. (PDF $289 \mathrm{~kb}$ )

Additional file 2: Figure S2. Cultivation temperature, not assay temperature, modulates Steinernema carpocapsae olfactory behavior gradually across temperature ranges. A. Ste. carpocapsae IJs were cultivated at $15^{\circ} \mathrm{C}, 20^{\circ} \mathrm{C}$, room temperature $\left(22 \pm 1{ }^{\circ} \mathrm{C}\right)$, or $25^{\circ} \mathrm{C}$ and tested 21 days after host-emergence. Olfactory behaviors changed gradually and consistently within the temperature range; $n=6-20$ trials for each condition. B. IJs were cultivated at $15^{\circ} \mathrm{C}$ and assayed at day 28 at either room temperature or $15^{\circ} \mathrm{C}$. IJs exhibited slightly more robust responses when assayed at $15^{\circ} \mathrm{C}$, but the valence of the response to each odorant was the same regardless of the assay temperature. ${ }^{*} P<$
0.05, two-way ANOVA with Sidak's post-test; $n=6$ trials for each condition. C. $25^{\circ} \mathrm{C}$ IJs that were temperature-swapped to $15^{\circ} \mathrm{C}$ (right) or maintained at $25{ }^{\circ} \mathrm{C}$ (left) for 2 weeks were assayed at room temperature or the incubation temperature. A valence change was observable regardless of the assay temperature. Although the assay temperature did not affect valence, the temperature-swapped IJs showed a weaker response to 1-hexanol when assayed at room temperature compared to $15^{\circ} \mathrm{C}$. ${ }^{* *} P<0.001$, two-way ANOVA with Sidak's post-test; $n=6-10$ trials for each condition. For all graphs, error bars represent standard error of the mean (SEM). Mean, $n$, and SEM values for each assay are listed in Additional file 7: Dataset S1. (PDF 415 kb)

Additional file 3: Figure S3. Temperature-induced changes in sensory valence are consistent across $\mathrm{CO}_{2}$ and odorant concentrations in Steinernema carpocapsae. A. Responses of infective juveniles (IJs) to various $\mathrm{CO}_{2}$ concentrations. $\mathrm{CO}_{2}$ was attractive for IJs across concentrations regardless of age or temperature treatment, although $25^{\circ} \mathrm{C} \mathrm{IJs} \mathrm{showed} \mathrm{an}$ increased response to $0.5 \% \mathrm{CO}_{2}$ at day 14 compared to day $0 .{ }^{*} P<0.05$ relative to day $0 \mathrm{IJS}$; two-way ANOVA with Dunnett's post-test; $n=6-10$ trials for each condition. B. Responses to different concentrations of 1-hexanol and 2-propanone were compared for day $0 \mathrm{IJS}$ maintained at $25^{\circ} \mathrm{C}$, day 14 IJs that were temperature-swapped from $25^{\circ} \mathrm{C}$ to $15^{\circ} \mathrm{C}$ on day 0 , and day $14 \mathrm{IJs}$ maintained at $25^{\circ} \mathrm{C}$. Responses of consistent valence were observed across concentrations. Data for undiluted concentrations are from Fig. 3. Responses of $25^{\circ} \mathrm{C}$ IJs to 2-propanone were significantly different between day 0 and day 14 at $10^{-4}(P<0.05)$ and $10^{-5}(P<0.01)$ concentrations in a two-way ANOVA with Sidak's post-test, comparing $10^{\circ}$ through $10^{-6}$ dilutions between $25{ }^{\circ} \mathrm{C}$ day 0 and $25^{\circ} \mathrm{C}$ day $14 \mathrm{IJs} ; \mathrm{n}=6-22$ trials for each condition. C. IJs exhibit olfactory plasticity in response to odor blends. IJs were tested for their response to three different mixes of odorants. Mix 1 contained $10^{-1}$ dilutions of methyl acetate, 1-propanol, and 2-propanone; Mix 2 contained $10^{-1}$ dilutions of 1-hexanol, 6-methyl-5-hepten2-one, and methyl salicylate; and Mix 3 contained $10^{-1}$ dilutions of 1-hexanol, 7-octenoic acid, and 2,2,4-trimethylpentane. ${ }^{* *} P<0.001$ relative to day $0 \mathrm{IJS}$; two-way ANOVA with Dunnett's post-test; $n=8$ trials for each condition. For all graphs, error bars represent standard error of the mean (SEM). Mean, $n$, and SEM values for each assay are listed in Additional file 7: Dataset S1. (PDF 428 kb)

Additional file 4: Figure S4. Olfactory plasticity occurs in individual infective juveniles (IJs), is not affected by cultivation density, and occurs in multiple strains of Steinernema carpocapsae. A. Temperature-induced changes in sensory valence occur in individual IJs. $25^{\circ} \mathrm{C}$ IJs that were repelled by 2-propanone on day 0 were collected and cultured at either $15^{\circ} \mathrm{C}$ or $25^{\circ} \mathrm{C}$ for 2 weeks, and then re-tested on day 14 using a modified scoring method (left). The IJs that were temperature-swapped from $25^{\circ} \mathrm{C}$ to $15^{\circ} \mathrm{C}$ showed opposite olfactory preferences compared to those maintained at $25^{\circ} \mathrm{C}$. ${ }^{* * *} P<0.001$, unpaired $t$-test; $n=6$ trials for each condition. Red bar $=1 \mathrm{~cm}$. B. Cultivation density does not affect temperature-induced sensory valence changes; $25^{\circ} \mathrm{C}$ day 0 Ste. carpocapsae IJs were collected and stored at $15^{\circ} \mathrm{C}$ at low density $(1 \mathrm{~J} / \mu \mathrm{LL})$, medium density $(6 \mathrm{~J} / \mu \mathrm{L})$, or high density $(25 \mathrm{~J} / \mu \mathrm{L})$ and tested for their response to 2-propanone and 1-hexanol after 2 weeks of storage. No significant effects of cultivation density $\left(F_{2,62}=0.2586, P=0.7730\right)$ or interaction $\left(F_{2,62}=1.912\right.$, $P=0.1565)$ were observed in a two-way ANOVA; $n=8-18$ trials for each condition. C. Multiple strains of Ste. carpocapsae exhibit temperaturedependent olfactory plasticity. In addition to the standard All strain, the DD136 and Sal strains [101] also exhibited temperature-induced sensory valence changes. A comparison of day $0 \mathrm{IJS}$ that were cultured at $25^{\circ} \mathrm{C}$, day $14 \mathrm{IJS}$ that were temperature-swapped from $25^{\circ} \mathrm{C}$ to $15^{\circ} \mathrm{C}$ on day 0 , and day $14 \mathrm{lJs}$ that were cultured at $25^{\circ} \mathrm{C}$ revealed both temperature- and age-dependent changes in olfactory responses. ${ }^{*} P$ $<0.01$; ${ }^{* * *} P<0.001$ relative to $25^{\circ} \mathrm{C}$ day $0 \mathrm{IJs}$, two-way ANOVA with Dunnett's post-test; $n=6-16$ trials for each condition. For all graphs, error bars represent standard error of the mean (SEM). Mean, $n$, and SEM values for each assay are listed in Additional file 7: Dataset S1. (PDF 529 kb)

Additional file 5: Figure S5. Temperature-induced valence changes in olfactory responses exhibit long-term stability. Steinernema carpocapsae infective juveniles (IJs) were infected at room temperature and stored at 
$15^{\circ} \mathrm{C}$ for up to 16 weeks. Their responses to a five-odor panel were recorded every 2 weeks after emergence from the host; $n=4-12$ trials for each condition. Error bars represent standard error of the mean (SEM). Mean, $n$, and SEM values for each assay are listed in Additional file 7: Dataset S1. (PDF $341 \mathrm{~kb})$

Additional file 6: Figure S6. Temperature and age affect olfactory behavior differently across entomopathogenic nematode species. Steinernema carpocapsae (A), Heterorhabditis bacteriophora (B), Ste. scapterisci (C), Ste. riobrave (D), H. indica (E), and Ste. feltiae (F) IJs were grown at $25^{\circ} \mathrm{C}$, and either temperature-swapped to $15^{\circ} \mathrm{C}$ on day 0 or maintained at $25^{\circ} \mathrm{C}$. All six species show age- and/or temperaturedependent changes in olfactory responses. In (A), data for 1-hexanol is from Fig. 3. In (B), data is from Fig. 4. ${ }^{*} P<0.05 ; * * P<0.01 ; * * * P<$ 0.001 relative to $25^{\circ} \mathrm{C}$ day $0 \mathrm{IJs}$, two-way ANOVA with Dunnett's posttest: $n=6-18$ trials for each condition. For all figures, error bars represent standard error of the mean (SEM). Mean, $n$, and SEM values for each assay are listed in Additional file 7: Dataset S1. (PDF $446 \mathrm{~kb}$ )

Additional file 7: Dataset S1. Compilation of mean, $n$, and standard error of the mean (SEM) values for all assays presented in this study. (XLSX $57 \mathrm{~kb})$

\section{Competing interests}

The authors declare that they have no competing interests.

\section{Authors' contributions}

$J \mathrm{~L}$ designed the study, conducted all experiments, and wrote the manuscript. ARD contributed a unique reagent and suggestions regarding interpretation of results. EAH designed the study and wrote the manuscript. All authors read and approved the final manuscript.

\section{Acknowledgements}

We thank David Shapiro-llan for nematodes; Junho Lee and Sungsu Park for micro-dirt chip PDMS molds; Amelia Miller for technical assistance; and Michelle Castelletto, Todd French, Ryo Okubo, and Kristen Yankura for insightful comments on the manuscript.

\section{Funding}

JL was a Howard Hughes Undergraduate Research Program Scholar. This work was funded by a Rita Allen Foundation Scholar Award and Searle Scholar Award to EAH.

\section{Author details}

'Department of Microbiology, Immunology, and Molecular Genetics, University of California, Los Angeles, California 90095, USA. ²Department of Nematology, University of California, Riverside, California 92521, USA.

\section{Received: 26 October 2015 Accepted: 22 April 2016}

\section{Published online: 06 May 2016}

\section{References}

1. Aktar MW, Sengupta D, Chowdhury A. Impact of pesticides use in agriculture: their benefits and hazards. Interdiscip Toxicol. 2009;2(1):1-12

2. Allen MT, Levy LS. Parkinson's disease and pesticide exposure-a new assessment. Crit Rev Toxicol. 2013;43(6):515-34.

3. Chopra AK, Sharma MK, Chamoli S. Bioaccumulation of organochlorine pesticides in aquatic system-an overview. Environ Monit Assess. 2011; 173(1-4):905-16

4. Tanner CM, Kamel F, Ross GW, Hoppin JA, Goldman SM, Korell M, et al. Rotenone, paraquat, and Parkinson's disease. Environ Health Perspect. 2011; 119(6):866-72

5. Duke SO, Cantrell CL, Meepagala KM, Wedge DE, Tabanca N, Schrader KK. Natural toxins for use in pest management. Toxins. 2010;2(8):1943-62.

6. Estruch JJ, Carozzi NB, Desai N, Duck NB, Warren GW, Koziel MG. Transgenic plants: an emerging approach to pest control. Nat Biotechnol. 1997;15(2): 137-41.

7. Costa-Font M, Gil JM, Traill WB. Consumer acceptance, valuation of and attitudes towards genetically modified food: review and implications for food policy. Food Policy. 2008;33(2):99-111.
8. Morandin LA, Winston ML, Franklin MT, Abbott VA. Lethal and sub-lethal effects of spinosad on bumble bees (Bombus impatiens Cresson). Pest Manag Sci. 2005;61(7):619-26.

9. Gaugler R, editor. Entomopathogenic nematology. New York: CABI Publishing; 2002.

10. Hominick WM. Biogeography. In: Gaugler R, editor. Entomopathogenic Nematology. New York: CABI Publishing; 2002. p. 115-43.

11. Kaya HK, Gaugler R. Entomopathogenic nematodes. Ann Rev Entomol. 1993; 38:181-206.

12. Shapiro-llan DI, Gaugler R. Production technology for entomopathogenic nematodes and their bacterial symbionts. J Ind Microbiol Biot. 2002;28:137-46.

13. Dillman AR, Sternberg PW. Entomopathogenic nematodes. Curr Biol. 2012; 22(11):R430-431.

14. Shapiro-llan DI, Gouge DH, Koppenhofer AM. Factors affecting commercial success: case studies in cotton, turf, and citrus. In: Gaugler R, editor. Entomopathogenic Nematology. New York: CABI Publishing; 2002. p. 333-55.

15. Georgis R, Koppenhofer AM, Lacey LA, Belair G, Duncan LW, Grewal PS, et al. Successes and failures in the use of parasitic nematodes for pest control. Biol Control. 2006:38:103-23.

16. Lacey LA, Georgis R. Entomopathogenic nematodes for control of insect pests above and below ground with comments on commercial production. J Nematol. 2012;44:218-25.

17. Crook M. The dauer hypothesis and the evolution of parasitism: 20 years on and still going strong. Int J Parasitol. 2014;44:1-8.

18. Grewal PS. Formulation and application technology. In: Gaugler R, editor. Entomopathogenic Nematology. New York: CAB International; 2002. p. 265-87.

19. Hotez P, Hawdon J, Schad GA. Hookworm larval infectivity, arrest and amphiparatenesis: the Caenorhabditis elegans Daf-c paradigm. Parasitol Today. 1993;9(1):23-6.

20. Rasmann S, Ali JG, Helder J, van der Putten WH. Ecology and evolution of soil nematode chemotaxis. J Chem Ecol. 2012;38(6):615-28.

21. Chaisson KE, Hallem EA. Chemosensory behaviors of parasites. Trends Parasitol. 2012;28(10):427-36.

22. Hallem EA, Dillman AR, Hong AV, Zhang Y, Yano JM, DeMarco SF, et al. A senson code for host seeking in parasitic nematodes. Curr Biol. 2011;21(5):377-83.

23. Dillman AR, Guillermin ML, Lee JH, Kim B, Sternberg PW, Hallem EA. Olfaction shapes host-parasite interactions in parasitic nematodes. Proc Natl Acad Sci U S A. 2012:109(35):E2324-2333.

24. O'Halloran DM, Burnell AM. An investigation of chemotaxis in the insect parasitic nematode Heterorhabditis bacteriophora. Parasitol. 2003;127(Pt 4): 375-85.

25. Kollner TG, Held M, Lenk C, Hiltpold I, Turlings TC, Gershenzon J, et al. A maize (E)-beta-caryophyllene synthase implicated in indirect defense responses against herbivores is not expressed in most American maize varieties. Plant Cell. 2008:20(2):482-94.

26. Rasmann S, Kollner TG, Degenhardt J, Hiltpold I, Toepfer S, Kuhlmann U, et al. Recruitment of entomopathogenic nematodes by insect-damaged maize roots. Nature. 2005;434(7034):732-7.

27. Laznik Z, Trdan S. An investigation on the chemotactic responses of different entomopathogenic nematode strains to mechanically damaged maize root volatile compounds. Exp Parasitol. 2013:134:349-55.

28. Ali JG, Alborn HT, Campos-Herrera R, Kaplan F, Duncan LW, RodriguezSaona C, et al. Subterranean, herbivore-induced plant volatile increases biological control activity of multiple beneficial nematode species in distinct habitats. PLoS One. 2012;7(6):e38146.

29. Ali JG, Alborn HT, Stelinski LL. Subterranean herbivore-induced volatiles released by citrus roots upon feeding by Diaprepes abbreviatus recruit entomopathogenic nematodes. J Chem Ecol. 2010;36:361-8.

30. Castelletto ML, Gang SS, Okubo RP, Tselikova AA, Nolan TJ, Platzer EG, et al. Diverse host-seeking behaviors of skin-penetrating nematodes. PLoS Pathog. 2014;10(8):e1004305.

31. Downes MJ, Griffin CT. Dispersal behavior and transmission strategies of the entomopathogenic nematodes Heterorhabditis and Steinernema. Biocontrol Sci Techn. 1996:6:347-56

32. Lewis EE. Behavioral ecology. In: Gauger R, editor. Entomopathogenic Nematology. New York: CAB International; 2002. p. 205-23.

33. Robinson AF. Optimal release rates for attracting Meloidogyne incognita, Rotylenchulus reniformis, and other nematodes to carbon dioxide in sand. J Nematol. 1995;27:42-50.

34. Koppenhofer AM, Fuzy EM. Attraction of four entomopathogenic nematodes to four white grub species. J Invert Path. 2008;99:227-34. 
35. Schmidt J, All JN. Attraction of Neoaplectana carpocapsae (Nematoda: Steinernematidae) to common excretory products of insects. Environ Entomol. 1979:8(1):55-61.

36. Schnebel EM, Grossfield J. Mating-temperature range in Drosophila. Evolution. 1984;38:1296-307.

37. Magalhães TR, Neves RA, Valentin JL, Figueiredo GM. Do the changes in temperature and light affect the functional response of the benthic mud snail Heleobia australis (Mollusca: Gastropoda)? An Acad Bras Cienc. 2014; 86(3):1197-206

38. Bennett AF. Thermal dependence of locomotor capacity. Am J Physiol. 1990;259(2 Pt 2):R253-258.

39. Gillooly JF, Brown JH, West GB, Savage VM, Charnov EL. Effects of size and temperature on metabolic rate. Science. 2001;293(5538):2248-51.

40. Golden JW, Riddle DL. A pheromone-induced developmental switch in Caenorhabditis elegans: temperature-sensitive mutants reveal a wild-type temperature-dependent process. Proc Natl Acad Sci U S A. 1984;81(3):819-23.

41. Murakami $\mathrm{S}$, Murakami $\mathrm{H}$. The effects of aging and oxidative stress on learning behavior in C. elegans. Neurobiol Aging. 2005;26(6):899-905

42. Tsui $D$, van der Kooy D. Serotonin mediates a learned increase in attraction to high concentrations of benzaldehyde in aged C. elegans. Learn Mem. 2008;15(11):844-55.

43. Matsuura T, Endo S, Iwamoto R, Takahashi H, Ichinose M. Developmental changes in chemotactic response and choice of two attractants, sodium acetate and diacetyl, in the nematode Caenorhabditis elegans. Comp Biochem Physiol A Mol Integr Physiol. 2007;147(4):920-7.

44. Mennella JA, Pepino MY, Reed DR. Genetic and environmental determinants of bitter perception and sweet preferences. Pediatrics. 2005;115(2):e216-222.

45. Jasmer DP, Goverse A, Smant G. Parasitic nematode interactions with mammals and plants. Annu Rev Phytopathol. 2003:41:245-70.

46. Boatin BA, Basanez MG, Prichard RK, Awadzi K, Barakat RM, Garcia HH, et al. A research agenda for helminth diseases of humans: towards control and elimination. PLoS Negl Trop Dis. 2012;6(4):e1547.

47. de Silva NR, Brooker S, Hotez PJ, Montresor A, Engels D, Savioli L. Soiltransmitted helminth infections: updating the global picture. Trends Parasitol. 2003;19(12):547-51.

48. Dillman AR, Chaston JM, Adams BJ, Ciche TA, Goodrich-Blair H, Stock SP, et al. An entomopathogenic nematode by any other name. PLoS Pathog. 2012;8(3):e1002527.

49. Poinar Jr GO. Origins and phylogenetic relationships of the entomophilic Rhabditids, Heterorhabditis and Steinernema. Fundam Appl Nematol. 1993;16:333-8.

50. Nguyen KB, Hunt DJ. editors. Entomopathogenic nematodes: systematics, phylogeny and bacterial symbionts. Nematology Monographs and Perspectives. Volume 5. Brill: Leiden; 2007.

51. Nguyen KB, Smart GC. Steinernema scapterisci n. sp. (Rhabditida: Steinernematidae). J Nematol. 1990;22:187-99.

52. Parkman JP, Frank JH, Nguyen KB, Smart GC. Inoculative release of Steinernema scapterisci (Rhabditida: Steinernematidae) to suppress pest mole crickets (Orthoptera: Gryllotalpidae) on golf courses. Environ Entomol. 1994; 23(5):1331-7.

53. Gaugler R, Campbell JF, Gupta P. Characterization and basis of enhanced host-finding in a genetically improved strain of Steinernema carpocapsae. J Invert Pathol. 1991;57:234-41.

54. Lee H, Choi MK, Lee D, Kim HS, Hwang H, Kim H, et al. Nictation, a dispersal behavior of the nematode Caenorhabditis elegans, is regulated by IL2 neurons. Nat Neurosci. 2012:15(1):107-12.

55. Schar F, Trostdorf U, Giardina F, Khieu V, Muth S, Marti H, et al. Strongyloides stercoralis: global distribution and risk factors. PLoS Negl Trop Dis. 2013;7(7):e2288.

56. Dormont L, Bessiere JM, Cohuet A. Human skin volatiles: a review. J Chem Ecol. 2013;39(5):569-78.

57. Shintoku Y, Kimura E, Kadosaka T, Hasegawa H, Kondo S, Itoh M, et al. Strongyloides ratti infection in the large intestine of wild rats, Rattus norvegicus. J Parasitol. 2005:91(5):1116-21.

58. Linn CE, Campbell MG, Roelofs WL. Temperature modulation of behavioural thresholds controlling male moth sex pheromone response specificity. Physiol Entomol. 1988;13:59-67.

59. Leinwand SG, Yang CJ, Bazopoulou D, Chronis N, Srinivasan J, Chalasani SH. Circuit mechanisms encoding odors and driving aging-associated behavioral declines in Caenorhabditis elegans. Elife. 2015;4:e10181.

60. Hanada T, Kashiwayanagi M, Kurihara K. Temperature increase abolishes ability of turtle olfactory receptors to discriminate similar odorant. Am J Physiol. 1994;266:R1816-23.
61. Kashiwayanagi M, Sasaki K, lida A, Saito H, Kurihara K. Concentration and membrane fluidity dependence of odor discrimination in the turtle olfactory system. Chem Senses. 1997;22(5):553-63.

62. Riveron J, Boto T, Alcorta E. The effect of environmental temperature on olfactory perception in Drosophila melanogaster. J Insect Physiol. 2009; 55(10):943-51.

63. Martin F, Riveron J, Alcorta E. Environmental temperature modulates olfactory reception in Drosophila melanogaster. J Insect Physiol. 2011;57(12):1631-42.

64. Kodama-Namba E, Fenk LA, Bretscher AJ, Gross E, Busch KE, de Bono M. Cross-modulation of homeostatic responses to temperature, oxygen and carbon dioxide in C. elegans. PLoS Genet. 2013;9(12):e1004011.

65. Dillon AB, Rolston AN, Meade CV, Downes MJ, Griffin CT. Establishment, persistence, and introgression of entomopathogenic nematodes in a forest ecosystem. Ecol Appl. 2008;18:735-47.

66. Hominick WM, Briscoe BR. Survey of 15 sites over 28 months for entomopathogenic nematodes (Rhabditida: Steinernematidae). Parasitol. 1990:100:289-94.

67. Susurluk A, Ehlers RU. Field persistence of the entomopathogenic nematode Heterorhabditis bacteriophora in different crops. BioControl. 2007:53:627-41.

68. Peters A. The natural host range of Steinernema and Heterorhabditis spp. and their impact on insect populations. Biocontrol Sci Techn. 1996:6:389-402.

69. Crossan J, Paterson S, Fenton A. Host availability and the evolution of parasite life-history strategies. Evolution. 2006;61:675-84.

70. Puza V, Mrabek Z. Seasonal dynamics of entomopathogenic nematodes of the genera Steinernema and Heterorhabditis as a response to abiotic factors and abundance of insect hosts. J Invert Path. 2005;89:116-22.

71. Tauber MJ, Tauber CA, Masaki S. Seasonal adaptations of insects. New York: Oxford University Press; 1986

72. Journey AM, Ostlie KR. Biological control of the western corn rootworm (Coleoptera: Chrysomelidae) using the entomopathogenic nematode, Steinernema carpocapsae. Environ Entomol. 2000;29(4):822-31.

73. Kuhn WR, Youngman RR, Wu S, Laub CA. Ecology, taxonomy, and pest management of billbugs (Coleoptera: Curculionidae) in orchardgrass of Virginia. J Integ Pest Mngmt. 2013;4:B1-5.

74. Meinke LJ, Sappington TW, Onstad DW, Guillemaud T, Miller NJ, Komáromi $J$, et al. Western corn rootworm (Diabrotica virgifera virgifera LeConte) population dynamics. Agric For Entomol. 2009;11:29-46.

75. Bruce TJ, Wadhams LJ, Woodcock CM. Insect host location: a volatile situation. Trends Plant Sci. 2005;10:269-74.

76. Gouinguene SP, Turlings TC. The effects of abiotic factors on induced volatile emissions in corn plants. Plant Physiol. 2002;129(3):1296-307.

77. Zhang Q-H, Birgersson G, Zhu J, Löfstedt C, Löfqvist J, Schlyter F. Leaf volatiles from nonhost deciduous trees: variation by tree species, season and temperature, and electrophysiological activity in Ips typographus. J Chem Ecol. 1999:25:1923-43.

78. Gemmill AW, Viney ME, Read AF. The evolutionary ecology of host-specificity: experimental studies with Strongyloides ratti. Parasitol. 2000;120:429-37.

79. Parkman JP, Hudson WG, Frank JH, Nguyen KB, Smart GC. Establishment and persistence of Steinernema scapterisci (Rhabditida: Steinernematidae) in field populations of Scapteriscus mole crickets (Orthoptera: Gryllotalpidae). J Entomol Sci. 1993;28:182-90.

80. Ferkin $\mathrm{MH}$, Sorokin ES, Johnston RE. Seasonal changes in scents and responses to them in meadow voles: evidence for the co-evolution of signals and response mechanisms. Ethol. 1995;100:89-98.

81. Heth G, Nevo E, Todrank J. Seasonal changes in urinary odors and in responses to them by blind subterranean mole rats. Physiol Behav. 1996;60:963-8.

82. Ponmanickam P, Palanivelu K, Govindaraj S, Baburajendran R, Habara Y, Archunan $\mathrm{G}$. Identification of testosterone-dependent volatile compounds and proteins in the preputial gland of rat Rattus norvegicus. Gen Comp Endocrinol. 2010;167(1):35-43.

83. Karg G, Sauer AE. Seasonal variation of pheromone concentration in mating disruption trials against European grape vine moth Lobesia botrana (Lepidoptera: Tortricidae) measured by EAG. J Chem Ecol. 1997;23(2):487-501.

84. Muller-Schwarze D, Silverstein RM. Chemical signals: vertebrates and aquatic invertebrates. New York: Plenum Press; 1980

85. Fushing H, Zhu L, Shapiro-llan DI, Campbell JF, Lewis EE. State-space based mass event-history model I: many decision-making agents with one target. Ann Appl Stat. 2008;2:1503-22.

86. Hay DB, Fenlon JS. A modified binomial model that describes the infection dynamics of the entomopathogenic nematode Steinernema feltiae (Steinernematidae; Nematoda). Parasitol. 1995;111:627-33. 
87. McGaughran A, Morgan K, Sommer RJ. Natural variation in chemosensation: lessons from an island nematode. Ecol Evol. 2013;3(16):5209-24.

88. Cinkornpumin JK, Wisidagama DR, Rapoport V, Go JL, Dieterich C, Wang X, Sommer RJ, Hong RL. A host beetle pheromone regulates development and behavior in the nematode Pristionchus pacificus. Elife. 2014;3:e03229.

89. Felix MA, Braendle C. The natural history of Caenorhabditis elegans. Curr Biol. 2010;20(22):R965-969.

90. Campbell JF, Gauger R. Nictation behaviour and its ecological implications in the host search strategies of entomopathogenic nematodes (Heterorhabditidae and Steinernematidae). Behaviour. 1993;126:155-69.

91. Wilson MJ, Ehlers R-U, Glazer I. Entomopathogenic nematode foraging strategies - is Steinernema carpocapsae really an ambush forager? Nematol. 2012;14:389-94

92. Biron D, Wasserman S, Thomas JH, Samuel AD, Sengupta P. An olfactory neuron responds stochastically to temperature and modulates Caenorhabditis elegans thermotactic behavior. Proc Natl Acad Sci U S A. 2008;105(31):11002-7.

93. Kuhara A, Okumura M, Kimata T, Tanizawa Y, Takano R, Kimura KD, et al. Temperature sensing by an olfactory neuron in a circuit controlling behavior of C. elegans. Science. 2008;320(5877):803-7.

94. Shapiro-llan DI, Lewis EE, Campbell JF, Kim-Shapiro DB. Directional movement of entomopathogenic nematodes in response to electrical field: effects of species, magnitude of voltage, and infective juvenile age. J Invert Path. 2012;109:34-40.

95. Shapiro-Ilan DI, Campbell JF, Lewis EE, Elkon JM, Kim-Shapiro DB. Directional movement of steinernematid nematodes in response to electrical current. J Invertebr Pathol. 2009;100(2):134-7.

96. Ilan T, Kim-Shapiro DB, Bock CH, Shapiro-llan DI. Magnetic and electric fields induce directional responses in Steinernema carpocapsae. Int J Parasitol. 2013;43(10):781-4.

97. Torr P, Heritage S, Wilson MJ. Vibrations as a novel signal for host location by parasitic nematodes. Int J Parasitol. 2004;34(9):997-9.

98. Granzer M, Hass W. Host-finding and host recognition of infective Ancylostoma caninum larvae. Int J Parasitol. 1991;21:429-40.

99. Fujimoto A, Lewis EE, Cobanoglu G, Kaya HK. Dispersal, infectivity and sex ratio of early- or late-emerging infective juveniles of the entomopathogenic nematode Steinernema carpocapsae. J Nematol. 2007;39:333-7.

100. Schafer TW, Skopic A. Parasites of the small intestine. Curr Gastroenterol Rep. 2006;8(4):312-20.

101. Shapiro-llan DI, Stuart R, McCoy CW. Comparison of beneficial traits among strains of the entomopathogenic nematode, Steinernema carpocapsae, for control of Curculio caryae (Coleoptera: Curculionidae). Biol Control. 2003;28: 129-36.

102. Campbell JF, Gaugler R. Inter-specific variation in entomopathogenic nematode foraging strategy: dichotomy or variation along a continuum? Fund Appl Nematol. 1997;20(4):393-8.

103. Shapiro-llan DI, Blackburn D, Duncan L, El-Borai FE, Koppenhöfer H, Tailliez $P$, et al. Characterization of biocontrol traits in Heterorhabditis floridensis: a species with broad temperature tolerance. J Nematol. 2014;46:336-45.

104. White GF. A method for obtaining infective nematode larvae from cultures. Science. 1927;66(1709):302-3.

105. Lok JB. Strongyloides stercoralis: a model for translational research on parasitic nematode biology. February 17, 2007. WormBook, ed. The C. elegans Research Community, WormBook. doi:10.1895/wormbook.1.134.1, http://www.wormbook.org.

106. Bargmann $\mathrm{Cl}$, Hartwieg E, Horvitz HR. Odorant-selective genes and neurons mediate olfaction in C. elegans. Cell. 1993;74(3):515-27.

107. Dillman AR, Cronin CJ, Tang J, Gray DA, Sternberg PW. A modified mole cricket lure and description of Scapteriscus borellii (Orthoptera: Gryllotalpidae) range expansion and calling song in California. Environ Entomol. 2014;43(1):146-56.

108. Ramot D, Johnson BE, Berry TL, Carnell L, Goodman MB. The parallel worm tracker: a platform for measuring average speed and drug-induced paralysis in nematodes. PLoS One. 2008;3(5):e2208.

109. Bal HK, Taylor RAJ, Grewal PS. Ambush foraging entomopathogenic nematodes employ 'sprinters' for long-distance dispersal in the absence of hosts. J Parasitol. 2014;100:422-32.

\section{Submit your next manuscript to BioMed Central and we will help you at every step:}

- We accept pre-submission inquiries

- Our selector tool helps you to find the most relevant journal

- We provide round the clock customer support

- Convenient online submission

- Thorough peer review

- Inclusion in PubMed and all major indexing services

- Maximum visibility for your research

Submit your manuscript at www.biomedcentral.com/submit 